\title{
A Short Survey on the Recent Fixed Point Results on $b$-Metric Spaces
}

\author{
ERDAL KARAPINAR*
}

ABSTRACT. The aim of this short survey is to collect and combine basic notions and results in the fixed point theory in the context of $b$-metric spaces. It is also aimed to show that there are still enough rooms for several researchers in this interesting direction and a huge application potential.

Keywords: $b$-Metric space, Fixed point

2010 Mathematics Subject Classification: 47H10, 54H25, 46J10, $46 \mathrm{~J} 15$.

\section{INTRODUCTION AND PRELIMINARIES}

The notion of distance is as old as the history of humanity and it was first properly formulated by Euclid. Basically, Euclidean distance is defined to measure the space (or gap, or interval) between two points as the length of the straight line segment connecting them. Indeed, the notion of metric, axiomatically formulated by Maurice Fréchet [38], is a generalization form of the Euclid distance. On the other hand, the name is due to Felix Hausdorff [40].

It is evident that the notion of the metric is the corner stone of the the field of real analysis, complex analysis and functional analysis Taking the key role of the notion of the metric in mathematics and hence in quantitative sciences, it has been extended and generalized in several distinct directions by many authors. Consequently, several version, adaptation, extension and generalization of metric has been reported in the literature, for instance, 2-metric, D-metric, G-metric, S-metric, set-valued metric, fuzzy metric, symmetric, quasi-metric, partial metric, $b$-metric, ultrametric, dislocated metric, modular metric, Hausdorff metric, cone metric, multiplicative metric, and so on. It is worthy of note that not all these generalizations are real generalization, see e.g. $[4,9,36,37,46,55,76]$.

Clearly, it is not possible to consider all these notions in a short survey. In this work, we restrict ourselves on the merging of one of the most interesting generalization of a notion of metric, namely $b$-metric. Before state the definition of $b$-metric, we recall the notion of (standard) metric for the sake of self-containment.

Definition 1.1. For a nonempty set $M$, a (standard) metric is a function $m: M \times M \rightarrow \mathbb{R}_{0}^{+}=[0, \infty)$ such that

$\left(M_{0}\right) m(x, y) \geq 0$ (nonnegativity),

$\left(M_{1}\right) x=y \Rightarrow m(x, y)=0$ (self-distance),

$\left(M_{2}\right) m(x, y)=0 \Rightarrow x=y$ (indistancy),

$\left(M_{3}\right) m(x, y)=m(y, x)$ (symmetry), and

$\left(M_{4}\right) m(x, y) \leq m(x, z)+m(z, y)$ (triangularity),

Received: August 13, 2018; In revised form: August 16, 2018; Accepted: August 19, 2018

${ }^{*}$ Corresponding author: E. Karapinar; erdalkarapinar@yahoo.com

DOI: $10.33205 / \mathrm{cma} .453034$ 
for all $x, y, z \in M$. Here, the ordered pair $(M, m)$ is called a (standard) metric space.

Indeed, the notion of the metric can be expressed in two axioms, as follows.

(a1) $x=y \Rightarrow m(x, y)=0$ (self-distance),

(a2) $m(x, y) \leq m(x, z)+m(y, z)$ (triangularity),

for all $x, y, z \in M$. It is clear that $\left(M_{0}\right)-\left(M_{4}\right)$ are obtained from $(a 1)$ and $(a 2)$. On the other hand, we separately state the axioms to explain and emphasize the nature how one can attempt to generalize the notion of standard metric. For instance, the axioms $\left(M_{0}\right),\left(M_{2}\right)-\left(M_{4}\right)$ yield dislocated metric (also known as metric-like), the axioms $\left(M_{0}\right)-\left(M_{3}\right)$ provide the notion of symmetric. It is clear that the removing any conditions from $\left(M_{0}\right)-\left(M_{4}\right)$ propose a new notion.

In this study, we focus on an interesting generalization of the standard metric, so-called, $b$-metric. This metric was popular after the interesting papers of Czerwik $[34,35]$ and it has been attracted attention of the several researchers. Indeed, this notion was considered earlier by different authors, e.g. Bourbaki [29], Bakhtin [17], Heinhonen [44], Berinde [18] and so on.

What follows we recall the notion of $b$-metric.

Definition 1.2. ([17], [35]) Let $M$ be a set and let $s \geq 1$ be a given real number. A function $d$ : $M \times M \rightarrow \mathbb{R}_{0}^{+}$is said to be a b-metric if the following conditions are satisfied:

$\left(b M_{o}\right) d(x, y) \geq 0$ (nonnegativity),

$\left(b M_{1}\right) x=y \Rightarrow d(x, y)=0$ (self-distance),

$\left(b M_{2}\right) d(x, y)=0 \Rightarrow x=y$ (indistancy),

$\left(b M_{3}\right) d(x, y)=d(y, x),($ symmetry),

$\left(b M_{4}\right) d(x, z) \leq s[d(x, y)+d(y, z)]$, (weakened triangularity).

for all $x, y, z \in M$. Furthermore, the ordered pair $(M, d)$ is called a b-metric space. We abbreviate the concept of the b-metric space as bMS.

As it is expected that each $b$-metric forms a metric by letting $s=1$. On the other hand, the converse is not case.

Example 1.1. (See e.g. [29].) Let $M=L^{p}[0,1]$ be the collections of all real functions $x(t)$ such that $\int_{0}^{1}|x(t)|^{p} d t<\infty$, where $t \in[0,1]$ and $0<p<1$. For the function $d: M \times M \rightarrow \mathbb{R}_{0}^{+}$defined by

$$
b(x, y):=\left(\int_{0}^{1}|x(t)-y(t)|^{p} d t\right)^{1 / p}, \text { for each } x, y \in L^{p}[0,1],
$$

the ordered pair $(M, b)$ forms a b-metric space with $s=2^{1 / p}$.

Example 1.2. Let $X$ be a set with the cardinal card $(X) \geq 3$. Suppose that $M=X_{1} \cup X_{2}$ is a partition of $X$ such that card $\left(X_{1}\right) \geq 2$. Let $s>1$ be arbitrary. Then, the functional $d: M \times M \rightarrow[0, \infty)$ defined by:

$$
d(x, y):= \begin{cases}0, & x=y \\ 2 s, & x, y \in M_{1} \\ 1, & \text { otherwise. }\end{cases}
$$

is a b-metric on $X$ with coefficient $s>1$.

Example 1.3. (See e.g. [29].) Let $p \in(0,1)$ and let

$$
M=l_{p}(\mathbb{R})=\left\{x=\left\{x_{n}\right\} \subset \mathbb{R} \text { such that } \sum_{n=1}^{\infty}\left|x_{n}\right|^{p}<\infty\right\} .
$$


Define $d(x, y): M \times M \rightarrow[0, \infty)$ by

$$
d(x, y)=\left(\sum_{n=1}^{\infty}\left|x_{n}-y_{n}\right|^{p}\right)^{1 / p} .
$$

Then $(X, d)$ is a b-metric space with $s=2^{1 / p}$.

The special case of the example above can be the following:

Example 1.4. Let $M=\mathbb{R}$. The function $d: \mathbb{R} \times \mathbb{R} \rightarrow[0, \infty)$ defined as

$$
d(x, y)=|x-y|^{2},
$$

is a b-metric on $\mathbb{R}$. Clearly, the first two conditions are satisfied. For the third condition, we have

$$
\begin{aligned}
|x-y|^{2} & =|x-z+z-y|^{2}=|x-z|^{2}+2|x-z||z-y|+|z-y|^{2} \\
& \leq 2\left[|x-z|^{2}+|z-y|^{2}\right]
\end{aligned}
$$

since

$$
2|x-z||z-y| \leq|x-z|^{2}+|z-y|^{2} .
$$

Example 1.5. Let $M=\{0,1,2\}$ and $d: M \times M \rightarrow \mathbb{R}_{+}$such that $d(0,1)=d(1,0)=d(0,2)=$ $d(2,0)=1, d(1,2)=d(2,1)=\alpha \geq 2, d(0,0)=d(1,1)=d(2,2)=0$. Then

$$
d(x, y) \leq \frac{\alpha}{2}[d(x, z)+d(z, y)], \text { for } x, y, z \in M \text {. }
$$

Example 1.6. Let $E$ be a Banach space and $0_{E}$ be the zero vector of $E$. Let $P$ be a cone in $E$ with $\operatorname{int}(P) \neq \emptyset$ and $\preceq$ be a partial ordering with respect to $P$. Let $X$ be a non-empty set. Suppose the mapping $d: X \times X \rightarrow E$ satisfies:

(M1) $0 \preceq d(x, y)$ for all $x, y \in X$,

(M2) $d(x, y)=0$ if and only if $x=y$,

(M3) $d(x, y) \preceq d(x, z)+d(z, y)$, for all $x, y \in X$,

$(M 4) d(x, y)=d(y, x)$ for all $x, y \in X$,

then $d$ is called cone metric on $X$, and the pair $(X, d)$ is called a cone metric space (CMS).

Let $E$ be a Banach space and $P$ be a normal cone in $E$ with the coefficient of normality denoted by $K$. Let $D: X \times X \rightarrow[0, \infty)$ be defined by $D(x, y)=\|d(x, y)\|$, where $d: X \times X \rightarrow E$ is a cone metric space. Then $(X, D)$ is a $b$-metric space with constant $s:=K \geq 1$.

The basic topological properties (convergence, completeness, etc.) have been observed by the mimic of the standard metric versions. Next, we recollect some essential notions together with the basic observations. Each $b$-metric $d$ on a non-empty set $M$ have a topology $\tau_{d}$ that was generated by the family of open balls

$$
B_{d}(x, \varepsilon)=\{y \in M:|d(x, y)-d(x, x)|<\varepsilon,\} \text { for all } x \in M \text { and } \varepsilon>0 .
$$

In the frame of the $b$-metric $(M, d)$, a given sequence $\left\{x_{n}\right\}$ converges to a point $x \in M$ if the following limit exists

$$
\lim _{n \rightarrow \infty} d\left(x_{n}, x\right)=0 .
$$

As it is expected, a sequence $\left\{x_{n}\right\}$ is said to be Cauchy if the following limit

$$
L=\lim _{n \rightarrow \infty} d\left(x_{n}, x_{m}\right)=0 .
$$

Furthermore, a pair $(M, d)$ is called complete $b$-metric space if for each Cauchy sequence $\left\{x_{n}\right\}$ is convergent, that is, there is some $x \in M$ such that

$$
\lim _{n \rightarrow \infty} d\left(x_{n}, x\right)=0=\lim _{n \rightarrow \infty} d\left(x_{n}, x_{m}\right) .
$$


Let $\left(M, d_{1}\right)$ and $\left(K, d_{2}\right)$ be $b$-metric spaces. A mapping $T: M \rightarrow K$ is called continuous if

$$
\lim _{n \rightarrow \infty} d_{1}\left(x_{n}, x\right)=0=\lim _{n, m \rightarrow \infty} d_{1}\left(x_{n}, x_{m}\right),
$$

then we have

$$
\lim _{n \rightarrow \infty} d_{2}\left(T x_{n}, T x\right)=0=\lim _{n, m \rightarrow \infty} d_{2}\left(T x_{n}, T x_{m}\right) .
$$

Definition 1.3. Let $(M, d)$ be a b-metric space and $S$ be a subset of $M$. We say $S$ is open subset of $M$, if for all $x \in M$ there exists $r>0$ such that $B_{d}(x, r) \subseteq S$. Also, $F \subseteq X$ is a closed subset of $M$ if $(M \backslash F)$ is a open subset of $M$.

A mapping $\varphi:[0, \infty) \rightarrow[0, \infty)$ is called a comparison function if it is increasing and $\varphi^{n}(t) \rightarrow 0$, $n \rightarrow \infty$, for any $t \in[0, \infty)$. We denote by $\Phi$, the class of the comparison function $\varphi:[0, \infty) \rightarrow$ $[0, \infty)$. For more details and examples, see e.g. [20,71]. Among them, we recall the following essential result.

Lemma 1.1. (Berinde [20], Rus [71]) If $\varphi:[0, \infty) \rightarrow[0, \infty)$ is a comparison function, then:

(1) each iterate $\varphi^{k}$ of $\varphi, k \geq 1$, is also a comparison function;

(2) $\varphi$ is continuous at 0 ;

(3) $\varphi(t)<t$, for any $t>0$.

Later, Berinde [20] introduced the concept of $(c)$-comparison function in the following way.

Definition 1.4. (Berinde [20]) A function $\varphi:[0, \infty) \rightarrow[0, \infty)$ is said to be a $(c)$-comparison function if

$\left(c_{1}\right) \varphi$ is increasing,

$\left(c_{2}\right)$ there exists $k_{0} \in \mathbb{N}, a \in(0,1)$ and a convergent series of nonnegative terms $\sum_{k=1}^{\infty} v_{k}$ such that $\varphi^{k+1}(t) \leq a \varphi^{k}(t)+v_{k}$, for $k \geq k_{0}$ and any $t \in[0, \infty)$.

The notion of a $(c)$-comparison function was improved as a $(b)$-comparison function by Berinde [19] in order to extend some fixed point results to the class of $b$-metric space.

Definition 1.5. (Berinde [19]) Let $s \geq 1$ be a real number. A mapping $\varphi:[0, \infty) \rightarrow[0, \infty)$ is called a (b)-comparison function if the following conditions are fulfilled

(1) $\varphi$ is monotone increasing;

(2) there exist $k_{0} \in \mathbb{N}, a \in(0,1)$ and a convergent series of nonnegative terms $\sum_{k=1}^{\infty} v_{k}$ such that $s^{k+1} \varphi^{k+1}(t) \leq a s^{k} \varphi^{k}(t)+v_{k}$, for $k \geq k_{0}$ and any $t \in[0, \infty)$.

We denote by $\Psi_{b}$ for the class of $(b)$-comparison function $\varphi:[0, \infty) \rightarrow[0, \infty)$. It is evident that the concept of $(b)$-comparison function reduces to that of $(c)$-comparison function when $s=1$.

The following lemma has a crucial role in the proof of our main result.

Lemma 1.2. (Berinde [18]) If $\varphi:[0, \infty) \rightarrow[0, \infty)$ is a (b)-comparison function, then we have the following

(1) the series $\sum_{k=0}^{\infty} s^{k} \varphi^{k}(t)$ converges for any $t \in \mathbb{R}_{+}$; 
(2) the function $b_{s}:[0, \infty) \rightarrow[0, \infty)$ defined by $b_{s}(t)=\sum_{k=0}^{\infty} s^{k} \varphi^{k}(t), t \in[0, \infty)$, is increasing and continuous at 0 .

Remark 1.1. By the Lemma 1.2, we conclude that every (b)-comparison function is a comparison function and hence, by the Lemma 1.1, any (b)-comparison function $\phi$ satisfies $\phi(t)<t$.

We denote with $\Psi$ the family of nondecreasing functions $\psi:[0, \infty) \rightarrow[0, \infty)$ such that $\sum_{n=1}^{\infty} \psi^{n}(t)<\infty$ for each $t>0$ It is clear that if $\Psi \subset \Phi$ (see e.g. [43]) and hence, by Lemma 1.1 (3), for $\psi \in \Psi$ we have $\psi(t)<t$, for any $t>0$.

In this short survey, we collect the interesting fixed point theorems for single valued mapping in the frame of complete $b$-metric space. This survey can be considered the collection the attractive results in $[3,11,24]$.

\section{FIXED POINT OF $\alpha-\psi$-CONTRACTIVE MAPPINGS}

We start this section by recalling the definition of $\alpha-\psi$-contractive and $\alpha$-orbital admissible mappings introduced in [75].

Definition 2.6. (Samet et al. [75]) Let $(M, d)$ be a metric space and $T: M \rightarrow M$ be a given mapping. We say that $T$ is an $\alpha$ - $\psi$-contractive mapping if there exist two functions $\alpha: M \times M \rightarrow[0, \infty)$ and $\psi \in \Psi$ such that

$$
\alpha(x, y) d(T(x), T(y)) \leq \psi(d(x, y)) \text {, for all } x, y \in M .
$$

Remark 2.2. If $T: M \rightarrow M$ satisfies the Banach contraction principle, then $T$ is an $\alpha-\psi$-contractive mapping, where $\alpha(x, y)=1$ for all $x, y \in M$ and $\psi(t)=k t$ for all $t \geq 0$ and some $k \in[0,1)$.

Definition 2.7. (Samet et al. [75]) Let $T: M \rightarrow M$ and $\alpha: M \times M \rightarrow[0, \infty)$. We say that $T$ is $\alpha$-admissible if

$$
x, y \in M, \quad \alpha(x, y) \geq 1 \Longrightarrow \alpha(T(x), T(y)) \geq 1 .
$$

Let $\mathcal{F}_{T}(X)$ be the class of fixed points of a self-mapping $T$ defined on a non-empty set $X$, that is, $\mathcal{F}_{T}(X)=\{x \in M: T(x)=x\}$.

Example 2.7. (Samet et al. [75]) Let $M=(0,+\infty)$. Define $T: M \rightarrow M$ and $\alpha: M \times M \rightarrow[0, \infty)$ by

(1) $T(x)=\ln (x)$, for all $x \in M$ and $\alpha(x, y)= \begin{cases}2, & \text { if } x \geq y \\ 0, & \text { if } x<y\end{cases}$

Then $T$ is $\alpha$-admissible.

(2) $T(x)=\sqrt{x}$, for all $x \in M$ and $\alpha(x, y)= \begin{cases}e^{x-y}, & \text { if } x \geq y \text {; } \\ 0, & \text { if } x<y \text {. }\end{cases}$

Then $T$ is $\alpha$-admissible.

Example 2.8. Let $(M, \preceq)$ be a partially ordered set and $d$ be a metric on $X$ such that $(M, d)$ is complete. Let $T: M \rightarrow M$ be a nondecreasing mapping with respect to $\preceq$, that is $x, y \in M, x \preceq y \Longrightarrow T x \preceq T y$. Suppose that there exists $x_{0} \in M$ such that $x_{0} \preceq T x_{0}$. Define the mapping $\alpha: M \times M \rightarrow[0, \infty)$ by

$$
\alpha(x, y)=\left\{\begin{array}{l}
1 \text { if } x \preceq y \text { or } x \succeq y, \\
0 \text { otherwise. }
\end{array}\right.
$$

Then, $T$ is $\alpha$-admissible. Since there exists $x_{0} \in M$ such that $x_{0} \preceq T x_{0}$, we have $\alpha\left(x_{0}, T x_{0}\right) \geq 1$. On the other hand, for all $x, y \in M$, from the monotone property of $T$, we have

$$
\alpha(x, y) \geq 1 \Longrightarrow x \succeq y \text { or } x \preceq y \Longrightarrow T x \succeq T y \text { or } T x \preceq T y \Longrightarrow \alpha(T x, T y) \geq 1 .
$$


Thus $T$ is $\alpha$-admissible.

Theorem 2.1. (Samet et al. [75]) Let $(M, d)$ be a complete metric space and $T: M \rightarrow M$ be an $\alpha-\psi$-contractive mapping satisfying the following conditions:

(i) $T$ is $\alpha$-admissible;

(ii) there exists $x_{0} \in M$ such that $\alpha\left(x_{0}, T\left(x_{0}\right)\right) \geq 1$;

(iii) $T$ is continuous.

Then, $T$ has a fixed point, that is, there exists $x^{*} \in \mathcal{F}_{T}(X)$.

Theorem 2.2. (Samet et al. [75]) Let $(M, d)$ be a complete metric space and $T: M \rightarrow M$ be an $\alpha-\psi$-contractive mapping satisfying the following conditions:

(i) $T$ is $\alpha$-admissible;

(ii) there exists $x_{0} \in M$ such that $\alpha\left(x_{0}, T\left(x_{0}\right)\right) \geq 1$;

(iii) if $\left\{x_{n}\right\}$ is a sequence in $X$ such that $\alpha\left(x_{n}, x_{n+1}\right) \geq 1$ for all $n$ and $x_{n} \rightarrow x \in M$ as $n \rightarrow \infty$, then $\alpha\left(x_{n}, x\right) \geq 1$ for all $n$.

Then, $T$ has a fixed point, that is, there exists $x^{*} \in \mathcal{F}_{T}(X)$.

In what follows we recollect the concept of triangular $\alpha$-admissible mapping.

Definition 2.8. [52] A self-mapping $T: M \rightarrow M$ is called triangular $\alpha$-admissible if

$\left(T_{1}\right) T$ is $\alpha$-admissible,

$\left(T_{1}\right) \alpha(x, z) \geq 1, \alpha(z, y) \geq 1 \Longrightarrow \alpha(x, y) \geq 1, x, y, z \in M$.

First of all, we refine the notion of $\alpha$-admissible mapping by proposing the notion of $\alpha$ orbital admissible as follows.

Definition 2.9. [68] Let $T: M \rightarrow M$ be a self-mapping and $\alpha: M \times M \rightarrow[0, \infty)$ be a function. Then $T$ is said to be $\alpha$-orbital admissible if

$$
\text { (T3) } \alpha(x, T x) \geq 1 \Rightarrow \alpha\left(T x, T^{2} x\right) \geq 1 \text {. }
$$

Analogously, we refine the notion of triangular $\alpha$-admissible mapping by proposing the notion of triangular $\alpha$-orbital admissible in the following way.

Definition 2.10. [68] Let $T: M \rightarrow M$ be a self-mapping and $\alpha: M \times M \rightarrow[0, \infty)$ be a function. Then, $T$ is said to be triangular $\alpha$-orbital admissible if $T$ is $\alpha$-orbital admissible and

$$
\text { (T4) } \alpha(x, y) \geq 1 \text { and } \alpha(y, T y) \geq 1 \Rightarrow \alpha(x, T y) \geq 1 \text {. }
$$

As it was mentioned in [68], each $\alpha$-admissible mapping is an $\alpha$-orbital admissible mapping and each triangular $\alpha$-admissible mapping is a triangular $\alpha$-orbital admissible mapping. The converse is false, see e.g. ( [68], Example 7).

Definition 2.11. [68] Let $(M, d)$ be a b-metric space and $\alpha: X \times M \rightarrow M$ be a function. $X$ is said $\alpha$-regular, if for every sequence $\left\{x_{n}\right\}$ in $X$ such that $\alpha\left(x_{n}, x_{n+1}\right) \geq 1$ for all $n$ and $x_{n} \rightarrow x \in M$ as $n \rightarrow \infty$, there exists a subsequence $\left\{x_{n(k)}\right\}$ of $\left\{x_{n}\right\}$ with $\alpha\left(x_{n(k)}, x\right) \geq 1$ for all $k$.

Lemma 2.3. [68] Let $T: M \rightarrow M$ be a triangular $\alpha$-orbital admissible mapping. Assume that there exists $x_{0} \in M$ such that $\alpha\left(x_{0}, T x_{0}\right) \geq 1$. Define a sequence $\left\{x_{n}\right\}$ by $x_{n+1}=T x_{n}$ for each $n \in \mathbb{N}_{0}$. Then we have $\alpha\left(x_{n}, x_{m}\right) \geq 1$ for all $m, n \in \mathbb{N}$ with $n<m$.

First we give the following definition as a generalization of Definition 2.6. 
Definition 2.12. Let $(M, d)$ be a b-metric space and $T: M \rightarrow M$ be a given mapping. We say that $T$ is an $\alpha-\psi$-contractive mapping of type-(b) if there exist two functions $\alpha: M \times M \rightarrow[0, \infty)$ and $\psi \in \Psi_{b}$ such that

$$
\alpha(x, y) d(T(x), T(y)) \leq \psi(d(x, y)), \text { for all } x, y \in X .
$$

Our first main result is the following.

Theorem 2.3. Let $(M, d)$ be a complete b-metric space with constant $s>1$. Let $T: M \rightarrow M$ be an $\alpha-\psi$-contractive mapping of type-(b) satisfying the following conditions:

(i) $T$ is $\alpha$-admissible;

(ii) there exists $x_{0} \in M$ such that $\alpha\left(x_{0}, T\left(x_{0}\right)\right) \geq 1$;

(iii) $T$ is continuous.

Then the fixed point equation (3.15) has a solution, that is, there exists $x^{*} \in \mathcal{F}_{f}(X)$.

Proof. Let $x_{0} \in M$ such that $\alpha\left(x_{0}, T\left(x_{0}\right)\right) \geq 1$ (such a point exists from condition (ii)). Define the sequence $\left\{x_{n}\right\}$ in $X$ by

$$
x_{n+1}=T\left(x_{n}\right), \text { for all } n \in \mathbb{N} \cup\{0\} .
$$

If $x_{n}=x_{n+1}$ for some $n \in \mathbb{N} \cup\{0\}$, then $x^{*}=x_{n}$ is a fixed point for $T$ and the proof finishes. Hence we assume that

$$
x_{n} \neq x_{n+1} \text { for all } n \in \mathbb{N} \cup\{0\} .
$$

Since $T$ is $\alpha$-orbital admissible, we have:

$$
\alpha\left(x_{0}, x_{1}\right)=\alpha\left(x_{0}, T\left(x_{0}\right)\right) \geq 1 \Longrightarrow \alpha\left(T\left(x_{0}\right), T\left(x_{1}\right)\right)=\alpha\left(x_{1}, x_{2}\right) \geq 1 .
$$

By induction, we get

$$
\alpha\left(x_{n}, x_{n+1}\right) \geq 1, \text { for all } n \in \mathbb{N} \cup\{0\} .
$$

Applying the inequality (2.5) with $x=x_{n-1}$ and $y=x_{n}$, and using (2.7), we obtain:

$$
d\left(x_{n}, x_{n+1}\right)=d\left(T\left(x_{n-1}\right), T\left(x_{n}\right)\right) \leq \alpha\left(x_{n-1}, x_{n}\right) d\left(T\left(x_{n-1}\right), T\left(x_{n}\right)\right) \leq \psi\left(d\left(x_{n-1}, x_{n}\right)\right) .
$$

By induction, we get

$$
d\left(x_{n}, x_{n+1}\right) \leq \psi^{n}\left(d\left(x_{0}, x_{1}\right)\right), \text { for all } n \in \mathbb{N} \cup\{0\} .
$$

From (2.8) and using the triangular inequality, for all $p \geq 1$, we have:

$$
\begin{gathered}
d\left(x_{n}, x_{n+p}\right) \leq s d\left(x_{n}, x_{n+1}\right)+s^{2} d\left(x_{n+1}, x_{n+2}\right)+\ldots+s^{p-2} d\left(x_{n+p-3}, x_{n+p-2}\right) \\
\quad+s^{p-1} d\left(x_{n+p-2}, x_{n+p-1}\right)+s^{p} d\left(x_{n+p-1}, x_{n+p}\right) \\
\leq s \psi^{n}\left(d\left(x_{0}, x_{1}\right)\right)+s^{2} \psi^{n+1}\left(d\left(x_{0}, x_{1}\right)\right)+\ldots+s^{p-2} \psi^{n+p-3}\left(d\left(x_{0}, x_{1}\right)\right) \\
\quad+s^{p-1} \psi^{n+p-2}\left(d\left(x_{0}, x_{1}\right)\right)+s^{p-1} \psi^{n+p-1}\left(d\left(x_{0}, x_{1}\right)\right) \\
=\frac{1}{s^{n-1}}\left[s^{n} \psi^{n}\left(d\left(x_{0}, x_{1}\right)\right)+s^{n+1} \psi^{n+1}\left(d\left(x_{0}, x_{1}\right)\right)+\ldots+s^{n+p-2} \psi^{n+p-2}\left(d\left(x_{0}, x_{1}\right)\right)\right. \\
\left.\quad+s^{n+p-1} \psi^{n+p-1}\left(d\left(x_{0}, x_{1}\right)\right)\right] .
\end{gathered}
$$

Denoting $S_{n}=\sum_{k=0}^{n} s^{k} \psi^{k}\left(d\left(x_{0}, x_{1}\right)\right), n \geq 1$ we obtain:

$$
d\left(x_{n}, x_{n+p}\right) \leq \frac{1}{s^{n-1}}\left[S_{n+p-1}-S_{n-1}\right], n \geq 1, p \geq 1 .
$$


Due to the assumption (2.6) together with Lemma 1.2, we conclude that the series $\sum_{k=0}^{n} s^{k} \psi^{k}\left(d\left(x_{0}, x_{1}\right)\right)$ is convergent. Thus there exists $S=\lim _{n \rightarrow \infty} S_{n} \in[0, \infty)$. Regarding $s \geq 1$ and by (2.9), we obtain that $\left\{x_{n}\right\}_{n \geq 0}$ is a Cauchy sequence in the $b$-metric space $(M, d)$. Since $(M, d)$ is complete, there exists $x^{*} \in M$ such that $x_{n} \rightarrow x^{*}$ as $n \rightarrow \infty$. From the continuity of $T$, it follows that $x_{n+1}=T\left(x_{n}\right) \rightarrow T\left(x^{*}\right)$ as $n \rightarrow \infty$. By the uniqueness of the limit, we get $x^{*}=T\left(x^{*}\right)$, that is, $x^{*}$ is a fixed point of $T$.

In the following theorem, we able omit the continuity hypothesis of $T$ by adding a new condition.

Theorem 2.4. Let $(M, d)$ be a complete b-metric space with constant $s>1$. Let $T: M \rightarrow M$ be an $\alpha-\psi$-contractive mapping of type-(b) satisfying the following conditions:

(i) $T$ is $\alpha$-orbital admissible;

(ii) there exists $x_{0} \in M$ such that $\alpha\left(x_{0}, T\left(x_{0}\right)\right) \geq 1$;

(iii) if $\left\{x_{n}\right\}$ is a sequence in $X$ such that $\alpha\left(x_{n}, x_{n+1}\right) \geq 1$ for all $n$ and $x_{n} \rightarrow x \in M$ as $n \rightarrow \infty$, then $\alpha\left(x_{n}, x\right) \geq 1$ for all $n$.

Then the fixed point equation (3.15) has a solution.

Proof. Following the proof of Theorem 2.3, we know that $\left\{x_{n}\right\}$ is a Cauchy sequence in the complete $b$-metric space $(M, d)$. Then, there exists $x^{*} \in M$ such that $x_{n} \rightarrow x^{*}$ as $n \rightarrow \infty$. On the other, hand from (2.7) and the hypothesis (iii), we have

$$
\alpha\left(x_{n}, x^{*}\right) \geq 1, \text { for all } n \in \mathbb{N} .
$$

Now, using the triangular inequality, (2.5) and (2.10), we get

$$
\begin{aligned}
d\left(T\left(x^{*}\right), x^{*}\right) & \leq s\left[d\left(T\left(x^{*}\right), T\left(x_{n}\right)\right)+d\left(x_{n+1}, x^{*}\right)\right] \\
& \leq s\left[\alpha\left(x_{n}, x^{*}\right) d\left(T\left(x^{*}\right), T\left(x_{n}\right)\right)+d\left(x_{n+1}, x^{*}\right)\right] \\
& \leq s\left[\psi\left(d\left(x_{n}, x^{*}\right)\right)+d\left(x_{n+1}, x^{*}\right)\right] .
\end{aligned}
$$

Letting $n \rightarrow \infty$, since $\psi$ is continuous at $t=0$, we obtain $d\left(T\left(x^{*}\right), x^{*}\right)=0$, that is $x^{*}=$ $T\left(x^{*}\right)$.

To assure the uniqueness of the fixed point, we will consider the following hypothesis.

$$
(H) \text { : for all } x, y \in M \text {, there exists } z \in M \text { such that } \alpha(x, z) \geq 1 \text { and } \alpha(y, z) \geq 1 \text {. }
$$

Theorem 2.5. Adding condition $(H)$ to the hypotheses of Theorem 2.3 (resp. Theorem 2.4) we obtain uniqueness of the fixed point of $T$.

Proof. Suppose that $x^{*}$ and $y^{*}$ are two fixed point of $T$. From $(H)$, there exists $z \in M$ such that

$$
\alpha\left(x^{*}, z\right) \geq 1 \text { and } \alpha\left(y^{*}, z\right) \geq 1 \text {. }
$$

Since $T$ is $\alpha$-orbital admissible, from (2.11), we get

$$
\alpha\left(x^{*}, T^{n}(z)\right) \geq 1 \text { and } \alpha\left(y^{*}, T^{n}(z)\right) \geq 1 .
$$

Using (2.12) and (2.5), we have

$$
\begin{aligned}
d\left(x^{*}, T^{n}(z)\right) & =d\left(T\left(x^{*}\right), T\left(T^{n-1}(z)\right)\right) \leq \alpha\left(x^{*}, T^{n-1}(z)\right) d\left(T\left(x^{*}\right), T\left(T^{n-1}(z)\right)\right) \\
\leq & \psi\left(d\left(x^{*}, T^{n-1}(z)\right)\right) .
\end{aligned}
$$

This imply that

$$
d\left(x^{*}, T^{n}(z)\right) \leq \psi^{n}\left(d\left(x^{*}, z\right)\right), \text { for all } n \in \mathbb{N} .
$$


Then, letting $n \rightarrow \infty$, we have

$$
T^{n}(z) \rightarrow x^{*} .
$$

Similarly, using (2.12) and (2.5), we get

$$
T^{n}(z) \rightarrow y^{*} \text { as } n \rightarrow \infty .
$$

Using (2.13) and (2.14), the uniqueness of the limit gives us $x^{*}=y^{*}$. This finishes the proof.

Remark 2.3. Theorem 2.1 (respectively, Theorem 2.2) can be derived from Theorem 2.3 (respectively, Theorem 2.4) by taking $s=1$. Consequently, all results in [75] can be considered as a corollaries of our main results.

\section{ULAM-HYERS STABILITY RESULTS THROUGH THE FIXED POINT PROBLEMS}

Definition 3.13. Let $(M, d)$ be a metric space and $T: M \rightarrow M$ be an operator. By definition, the fixed point equation

$$
x=T(x)
$$

is called generalized Ulam-Hyers stable if and only if there exists $\psi: \mathbb{R}_{+} \rightarrow \mathbb{R}_{+}$which is increasing, continuous at 0 and $\psi(0)=0$ such that for every $\varepsilon>0$ and for each $w^{*} \in M$ an $\varepsilon$-solution of the fixed point equation (3.15), i.e. $w^{*}$ satisfies the inequality

$$
d\left(w^{*}, T\left(w^{*}\right)\right) \leq \varepsilon
$$

there exists a solution $x^{*} \in M$ of the equation (3.15) such that

$$
d\left(w^{*}, x^{*}\right) \leq \psi(\varepsilon) .
$$

If there exists $c>0$ such that $\psi(t)=c \cdot t$, for each $t \in \mathbb{R}_{+}$, then the fixed point equation (3.15) is said to be Ulam-Hyers stable.

For Ulam-Hyers stability results in the case of fixed point problems see M. F. Bota-Boriceanu, A. Petruşel [23], V. L. Lazăr [60], I. A. Rus [70], I. A. Rus [72].

Regarding the Ulam-Hyers stability problem the ideas given in T. P. Petru, A. Petruşel and J.-C. Yao [67] allow us to obtain the following result.

Theorem 3.6. Let $(M, d)$ be a complete b-metric space with constant $s>1$. Suppose that all the hypotheses of Theorem 2.5 hold and additionally that the function $\beta:[0, \infty) \rightarrow[0, \infty), \beta(r):=$ $r-s \psi(r)$ is strictly increasing and onto. Then

(a) the fixed point equation (3.15) is generalized Ulam-Hyers stable.

(b) Fix $(T)=\left\{x^{*}\right\}$ and if $x_{n} \in M, n \in \mathbb{N}$ are such that $d\left(x_{n}, T\left(x_{n}\right)\right) \rightarrow 0$, as $n \rightarrow \infty$, then $x_{n} \rightarrow x^{*}$, as $n \rightarrow \infty$, i.e. the fixed point equation (3.15) is well posed.

(c) If $g: M \rightarrow M$ is such that there exists $\eta \in[0, \infty)$ with

$$
d(T(x), g(x)) \leq \eta, \text { for all } x \in M,
$$

then

$$
y^{*} \in \operatorname{Fix}(g) \Longrightarrow d\left(x^{*}, y^{*}\right) \leq \beta^{-1}(s \cdot \eta) .
$$

Proof. (a) Since $T: M \rightarrow M$ is a Picard operator, so Fix $(T)=\left\{x^{*}\right\}$. Let $\varepsilon>0$ and $w^{*} \in M$ be a solution of (3.16), i.e,

$$
d\left(w^{*}, T\left(w^{*}\right)\right) \leq \varepsilon .
$$

Since $T$ is $\alpha-\psi$-contractive mapping of type- $(b)$ and since $x^{*} \in F i x(T)$, from $(H)$ there exists $w^{*} \in M$ such that $\alpha\left(x^{*}, w^{*}\right) \geq 1$, we obtain:

$$
d\left(x^{*}, w^{*}\right)=d\left(T\left(x^{*}\right), w^{*}\right) \leq s\left[d\left(T\left(x^{*}\right), T\left(w^{*}\right)\right)+d\left(T\left(w^{*}\right), w^{*}\right)\right]
$$




$$
\leq s\left[\alpha\left(x^{*}, w^{*}\right) d\left(T\left(x^{*}\right), T\left(w^{*}\right)\right)+\varepsilon\right] \leq s\left[\psi\left(d\left(x^{*}, w^{*}\right)\right)+\varepsilon\right] .
$$

Therefore,

$$
\beta\left(d\left(x^{*}, w^{*}\right)\right):=d\left(x^{*}, w^{*}\right)-s \psi\left(d\left(x^{*}, w^{*}\right)\right) \leq s \cdot \varepsilon \Longrightarrow d\left(x^{*}, w^{*}\right) \leq \beta^{-1}(s \cdot \varepsilon) .
$$

Consequently, the fixed point equation (3.15) is generalized Ulam-Hyers stable.

(b) Since $T$ is $\alpha-\psi$-contractive mapping of type- $(b)$ and since $x^{*} \in \operatorname{Fix}(T)$, from $(H)$ there exists $x_{n} \in M$ such that $\alpha\left(x^{*}, x_{n}\right) \geq 1$, we obtain:

$$
\begin{aligned}
& d\left(x_{n}, x^{*}\right) \leq s\left[d\left(x_{n}, T\left(x_{n}\right)\right)+d\left(T\left(x_{n}\right), x^{*}\right)\right]=s\left[d\left(x_{n}, T\left(x_{n}\right)\right)+d\left(T\left(x_{n}\right), T\left(x^{*}\right)\right)\right] \\
& \leq s\left[d\left(x_{n}, T\left(x_{n}\right)\right)+\alpha\left(x_{n}, x^{*}\right) d\left(T\left(x_{n}\right), T\left(x^{*}\right)\right)\right] \leq s\left[d\left(x_{n}, T\left(x_{n}\right)\right)+\psi\left(d\left(x_{n}, x^{*}\right)\right)\right] .
\end{aligned}
$$

Therefore

$$
\begin{gathered}
\beta\left(d\left(x_{n}, x^{*}\right)\right):=d\left(x_{n}, x^{*}\right)-s \psi\left(d\left(x_{n}, x^{*}\right)\right) \leq s d\left(x_{n}, T\left(x_{n}\right)\right) \rightarrow 0 \text { as } n \rightarrow \infty \\
\Longrightarrow d\left(x_{n}, x^{*}\right) \rightarrow 0 \text { as } n \rightarrow \infty \Longrightarrow x_{n} \rightarrow x^{*}, \text { as } n \rightarrow \infty .
\end{gathered}
$$

So, the fixed point equation (3.15) is well posed.

(c) Since $T$ is $\alpha$ - $\psi$-contractive mapping of type- $(b)$ and since $x^{*} \in F i x(T)$, from $(H)$ there exists $x \in M$ such that $\alpha\left(x^{*}, x\right) \geq 1$, we obtain:

$$
\begin{aligned}
& d\left(x, x^{*}\right) \leq s\left[d(x, T(x))+d\left(T(x), x^{*}\right)\right]=s\left[d(x, T(x))+d\left(T(x), T\left(x^{*}\right)\right)\right] \\
& \leq s\left[d(x, T(x))+\alpha\left(x, x^{*}\right) d\left(T(x), T\left(x^{*}\right)\right)\right] \leq s\left[d(x, T(x))+\psi\left(d\left(x, x^{*}\right)\right)\right] .
\end{aligned}
$$

Therefore

$$
\beta\left(d\left(x, x^{*}\right)\right):=d\left(x, x^{*}\right)-s \psi\left(d\left(x, x^{*}\right)\right) \leq s \cdot d(x, T(x)) .
$$

So, we have the following estimation

$$
d\left(x, x^{*}\right) \leq \beta^{-1}(s \cdot d(x, T(x))) .
$$

Writing (3.17) for $x:=y^{*}$ we get:

$$
d\left(x^{*}, y^{*}\right) \leq \beta^{-1}\left(s \cdot d\left(y^{*}, T\left(y^{*}\right)\right)\right)=\beta^{-1}\left(s \cdot d\left(s\left(y^{*}\right), T\left(y^{*}\right)\right)\right) \Longrightarrow d\left(x^{*}, y^{*}\right) \leq \beta^{-1}(s \cdot \eta) .
$$

\section{NON UNIQUE FIXED POINTS ON $b$-METRIC SPACES}

In this section, inspired by the well-known non-unique fixed point of Ćirić, we state and prove some new non-unique fixed point theorems in the setting of $b$-metric spaces. Our results improve the existence results in the literature, see e.g. [33,49,50,65]. We shall start to this section by recalling the notion of orbitally continuous.

Definition 4.14. A mapping $T$ on $b$-metric space $(M, d)$ is said to be orbitally continuous if $\lim _{i \rightarrow \infty} T^{n_{i}}(x)=$ $z$ implies $\lim _{i \rightarrow \infty} T\left(T^{n_{i}}(x)\right)=T z$. A b-metric space $(M, d)$ is called T-orbitally complete if every Cauchy sequence of the form $\left\{T^{n_{i}}(x)\right\}_{i=1}^{\infty}, x \in M$ converges in $(M, d)$.

Remark 4.4. It is evident that orbital continuity of $T$ yields orbital continuity of $T^{m}$ for any $m \in \mathbb{N}$.

Theorem 4.7. Let $T$ be an orbitally continuous self-map on the T-orbitally complete b-metric space $(M, d)$. If there is $\psi \in \Psi$ such that

$$
\min \{d(T x, T y), d(x, T x), d(y, T y)\}-\min \{d(x, T y), d(T x, y)\} \leq \psi(d(x, y)),
$$

for all $x, y \in M$, then for each $x_{0} \in M$ the sequence $\left\{T^{n} x_{0}\right\}_{n \in \mathbb{N}}$ converges to a fixed point of $T$. 
Proof. For an arbitrary $x \in M$, we shall construct an iterative sequence $\left\{x_{n}\right\}$ as follows:

$$
x_{0}:=x \text { and } x_{n}=T x_{n-1} \text { for all } n \in \mathbb{N} .
$$

We suppose that

$$
x_{n} \neq x_{n-1} \text { for all } n \in \mathbb{N} .
$$

Indeed, if for some $n \in \mathbb{N}$ we have the inequality $x_{n}=T x_{n-1}=x_{n-1}$, then, the proof is completed. By substituting $x=x_{n-1}$ and $y=x_{n}$ in the inequality (4.18), we derive that

$$
\begin{aligned}
& \min \left\{d\left(T x_{n-1}, T x_{n}\right), d\left(x_{n-1}, T x_{n-1}\right), d\left(x_{n}, T x_{n}\right)\right\} \\
& \quad-\min \left\{d\left(x_{n-1}, T x_{n}\right), d\left(T x_{n-1}, x_{n}\right)\right\} \leq \psi\left(d\left(x_{n-1}, x_{n}\right)\right) .
\end{aligned}
$$

It implies that

$$
\min \left\{d\left(x_{n}, x_{n+1}\right), d\left(x_{n}, x_{n-1}\right)\right\} \leq \psi\left(d\left(x_{n-1}, x_{n}\right)\right) .
$$

Since $\psi(t)<t$ for all $t>0$, the case $d\left(x_{n}, x_{n-1}\right) \leq \psi\left(d\left(x_{n-1}, x_{n}\right)\right)$ is impossible. Thus, we have

$$
d\left(x_{n}, x_{n+1}\right) \leq \psi\left(d\left(x_{n-1}, x_{n}\right)\right) .
$$

Applying Remark 1.1 recurrently, we find that

$$
d\left(x_{n}, x_{n+1}\right) \leq \psi\left(d\left(x_{n-1}, x_{n}\right)\right) \leq \psi^{2}\left(d\left(x_{n-2}, x_{n-1}\right)\right) \leq \cdots \leq \psi^{n}\left(d\left(x_{0}, x_{1}\right)\right) .
$$

By Lemma 1.2, we deduce that

$$
\lim _{n \rightarrow \infty} d\left(x_{n+1}, x_{n}\right)=0 .
$$

In what follow we shall prove that the sequence $\left\{x_{n}\right\}$ is Cauchy.

Consider $d\left(x_{n}, x_{n+k}\right)$ for $k \geq 1$. By using the triangle inequality (b3) again and again, we get the following approximation

$$
\begin{aligned}
d\left(x_{n}, x_{n+k}\right) & \leq s\left[d\left(x_{n}, x_{n+1}\right)+d\left(x_{n+1}, x_{n+k}\right)\right] \\
& \leq s d\left(x_{n}, x_{n+1}\right)+s\left\{s\left[d\left(x_{n+1}, x_{n+2}\right)+d\left(x_{n+2}, x_{n+k}\right)\right]\right\} \\
& =s d\left(x_{n}, x_{n+1}\right)+s^{2} d\left(x_{n+1}, x_{n+2}\right)+s^{2} d\left(x_{n+2}, x_{n+k}\right) \\
& \vdots \\
& \leq s d\left(x_{n}, x_{n+1}\right)+s^{2} d\left(x_{n+1}, x_{n+2}\right)+\ldots \\
& +s^{k-1} d\left(x_{n+k-2}, x_{n+k-1}\right)+s^{k-1} d\left(x_{n+k-1}, x_{n+k}\right) \\
& \leq s d\left(x_{n}, x_{n+1}\right)+s^{2} d\left(x_{n+1}, x_{n+2}\right)+\ldots \\
& +s^{k-1} d\left(x_{n+k-2}, x_{n+k-1}\right)+s^{k} d\left(x_{n+k-1}, x_{n+k}\right),
\end{aligned}
$$

since $s \geq 1$. Combining (4.24) and (4.26) we derive that

$$
\begin{aligned}
d\left(x_{n}, x_{n+k}\right) & \leq s \psi^{n}\left(d\left(x_{0}, x_{1}\right)\right)+s^{2} \psi^{n+1} d\left(x_{0}, x_{1}\right)+\ldots \\
& +s^{k-1} \psi^{n+k-2}\left(d\left(x_{0}, x_{1}\right)\right)+s^{k} \psi^{n+k-1}\left(d\left(x_{0}, x_{1}\right)\right) \\
& =\frac{1}{s^{n-1}}\left[s^{n} \psi^{n}\left(d\left(x_{0}, x_{1}\right)\right)+s^{n+1} \psi^{n+1} d\left(x_{0}, x_{1}\right)+\ldots\right. \\
& \left.+s^{n+k-2} \psi^{n+k-2}\left(d\left(x_{0}, x_{1}\right)\right)+s^{n+k-1} \psi^{n+k-1}\left(d\left(x_{0}, x_{1}\right)\right)\right] .
\end{aligned}
$$

Consequently, we have

$$
d\left(x_{n}, x_{n+k}\right) \leq \frac{1}{s^{n-1}}\left[P_{n+k-1}-P_{n-1}\right], \quad n \geq 1, k \geq 1,
$$


where $P_{n}=\sum_{j=0}^{n} s^{j} \psi^{j}\left(d\left(x_{0}, x_{1}\right)\right), n \geq 1$. From Lemma 1.2, the series $\sum_{j=0}^{\infty} s^{j} \psi^{j}\left(d\left(x_{0}, x_{1}\right)\right)$ is convergent and since $s \geq 1$, upon taking limit $n \rightarrow \infty$ in (4.28) we get

$$
\lim _{n \rightarrow \infty} d\left(x_{n}, x_{n+k}\right) \leq \lim _{n \rightarrow \infty} \frac{1}{s^{n-1}}\left[P_{n+k-1}-P_{n-1}\right]=0 .
$$

We conclude that the sequence $\left\{x_{n}\right\}$ is Cauchy in $(M, d)$.

Owing to the construction $x_{n}=T^{n} x_{0}$ and the fact that $(X, p)$ is $T$-orbitally complete, there is $z \in M$ such that $x_{n} \rightarrow z$. Due to the orbital continuity of $T$, we conclude that $x_{n} \rightarrow T z$. Hence $z=T z$ which terminates the proof.

Corollary 4.1. Let $T$ be an orbitally continuous self-map on the T-orbitally complete b-metric space $(M, d)$. If there exists $k \in[0,1)$ such that

$$
\min \{d(T x, T y), d(x, T x), d(y, T y)\}-\min \{d(x, T y), d(T x, y)\} \leq k d(x, y),
$$

for all $x, y \in M$, then for each $x_{0} \in M$ the sequence $\left\{T^{n} x_{0}\right\}_{n \in \mathbb{N}}$ converges to a fixed point of $T$.

If we take $s=1$ in the previous corollary, we get the famous non-unique fixed point theorem of Ćirić.

Corollary 4.2. [Non-unique fixed point theorem of Ćirić [33]] Let $T$ be an orbitally continuous self-map on the $T$-orbitally complete standard metric space $(M, d)$. If there is $k \in[0,1)$ such that

$$
\min \{d(T x, T y), d(x, T x), d(y, T y)\}-\min \{d(x, T y), d(T x, y)\} \leq k d(x, y),
$$

for all $x, y \in M$, then for each $x_{0} \in M$ the sequence $\left\{T^{n} x_{0}\right\}_{n \in \mathbb{N}}$ converges to a fixed point of $T$.

Remark 4.5. Regarding the Example 1.6, we deduce that the analog of Ćiric non-unique fixed point theorem, Corollary 4.2, in the setting of cone metric space with normal cone, is still valid (see e.g. [50]).

Theorem 4.8. Let $T$ be an orbitally continuous self-map on the T-orbitally complete b-metric space $(M, d)$.

Suppose there exist real numbers $a_{1}, a_{2}, a_{3}, a_{4}, a_{5}$ and a self mapping $T: M \rightarrow M$ satisfies the conditions

$$
0 \leq \frac{a_{4}-a_{2}}{a_{1}+a_{2}}<1, a_{1}+a_{2} \neq 0, a_{1}+a_{2}+a_{3}>0 \text { and } 0 \leq a_{3}-a_{5}
$$

$$
a_{1} d(T x, T y)+a_{2}[d(x, T x)+d(y, T y)]+a_{3}[d(y, T x)+d(x, T y)] \leq a_{4} d(x, y)+a_{5} d\left(x, T^{2} x\right)
$$

hold for all $x, y \in M$. Then, $T$ has at least one fixed point.

Proof. Take $x_{0} \in M$ be arbitrary. Construct a sequence $\left\{x_{n}\right\}$ as follows:

$$
x_{n+1}:=T x_{n} \quad n=0,1,2, \ldots
$$

When we substitute $x=x_{n}$ and $y=x_{n+1}$ on the inequality (4.32), it implies that (4.34)

$$
\begin{gathered}
a_{1} d\left(T x_{n}, T x_{n+1}\right)+a_{2}\left[d\left(x_{n}, T x_{n}\right)+d\left(x_{n+1}, T x_{n+1}\right)\right]+a_{3}\left[d\left(x_{n+1}, T x_{n}\right)+d\left(x_{n}, T x_{n+1}\right)\right] \\
\leq a_{4} d\left(x_{n}, x_{n+1}\right)+a_{5} d\left(x_{n}, T^{2} x_{n}\right)
\end{gathered}
$$

for all $a_{1}, a_{2}, a_{3}, a_{4}, a_{5}$ that satisfy (4.31). Due to (4.33), the statement (4.34) turns into

$$
\begin{gathered}
a_{1} d\left(x_{n+1}, x_{n+2}\right)+a_{2}\left[d\left(x_{n}, x_{n+1}\right)+d\left(x_{n+1}, x_{n+2}\right)\right]+a_{3}\left[d\left(x_{n+1}, x_{n+1}\right)+d\left(x_{n}, x_{n+2}\right)\right] \\
\leq a_{4} d\left(x_{n}, x_{n+1}\right)+a_{5} d\left(x_{n}, x_{n+2}\right) .
\end{gathered}
$$


By a simple calculation, one can get

$$
\left(a_{1}+a_{2}\right) d\left(x_{n+1}, x_{n+2}\right)+\left(a_{3}-a_{5}\right) d\left(x_{n}, x_{n+2}\right) \leq\left(a_{4}-a_{2}\right) d\left(x_{n}, x_{n+1}\right)
$$

which implies

$$
d\left(x_{n+1}, x_{n+2}\right) \leq k d\left(x_{n}, x_{n+1}\right),
$$

where $k=\frac{a_{4}-a_{2}}{a_{1}+a_{2}}$. Due to (4.31), we have $0 \leq k<1$. Taking account of (4.37), we get inductively

$$
d\left(x_{n}, x_{n+1}\right) \leq k d\left(x_{n-1}, x_{n}\right) \leq k^{2} d\left(x_{n-2}, x_{n-1}\right) \leq \cdots \leq k^{n} d\left(x_{0}, x_{1}\right) .
$$

We shall prove that $\left(x_{n}\right)_{n \in \mathbb{N}}$ is a Cauchy sequence.

$$
\begin{aligned}
d\left(x_{n}, x_{n+p}\right) & \leq s \cdot d\left(x_{n}, x_{n+1}\right)+s^{2} \cdot d\left(x_{n+1}, x_{n+2}\right)+\ldots+s^{p-2} \cdot d\left(x_{n+p-3}, x_{n+p-2}\right)+ \\
& +s^{p-1} \cdot d\left(x_{n+p-2}, x_{n+p-1}\right)+s^{p} \cdot d\left(x_{n+p-1}, x_{n+p}\right) \\
& \leq s \cdot k^{n} \cdot d\left(x_{0}, x_{1}\right)+s^{2} \cdot k^{n+1} \cdot d\left(x_{0}, x_{1}\right)+\ldots+ \\
& +s^{p-2} \cdot k^{n+p-3} \cdot d\left(x_{0}, x_{1}\right)+s^{p-1} \cdot k^{n+p-2} \cdot d\left(x_{0}, x_{1}\right)+ \\
& +s^{p} \cdot k^{n+p-1} \cdot d\left(x_{0}, x_{1}\right) \\
& =\frac{1}{s^{n} \cdot k} \cdot\left[s^{n+1} \cdot k^{n+1} \cdot d\left(x_{0}, x_{1}\right)+\ldots+s^{n+p-1} \cdot k^{n+p-1} \cdot d\left(x_{0}, x_{1}\right)+\right. \\
& \left.+s^{n+p} \cdot k^{n+p} \cdot d\left(x_{0}, x_{1}\right)\right] \\
& \leq \frac{1}{s^{n} \cdot k} \cdot\left[s^{n+1} \cdot k^{n+1} \cdot d\left(x_{0}, x_{1}\right)+\ldots+s^{n+p} \cdot k^{n+p} \cdot d\left(x_{0}, x_{1}\right)\right] \\
& =\frac{1}{s^{n} \cdot k} \cdot \sum_{i=n+1}^{n+p} s^{i} \cdot k^{i} \cdot d\left(x_{0}, x_{1}\right) \\
& <\frac{1}{s^{n} k} \cdot \sum_{i=n+1}^{\infty} s^{i} \cdot k^{i} \cdot d\left(x_{0}, x_{1}\right) .
\end{aligned}
$$

The precedent inequality is

$$
d\left(x_{n}, x_{n+p}\right)<\frac{1}{s^{n} k} \cdot \sum_{i=n+1}^{\infty} s^{i} \cdot k^{i} \cdot d\left(x_{0}, x_{1}\right) . \longrightarrow 0 \text { as } n \longrightarrow \infty .
$$

Thus $\left(x_{n}\right)_{n \in \mathbb{N}}$ is a Cauchy sequence.

As in the proof of previous theorem, regarding the construction $x_{n}=T^{n} x_{0}$ together with the fact that $(X, p)$ is $T$-orbitally complete, there is $z \in M$ such that $x_{n} \rightarrow z$. Again by the orbital continuity of $T$, we deduce that $x_{n} \rightarrow T z$. Hence $z=T z$.

Theorem 4.8 is still valid in the context of standard metric space.

Corollary 4.3. (See [49]) Let $T$ be an orbitally continuous self-map on the T-orbitally complete standard metric space $(M, d)$.

Suppose there exist real numbers $a_{1}, a_{2}, a_{3}, a_{4}, a_{5}$ and a self mapping $T: M \rightarrow M$ satisfies the conditions

$$
0 \leq \frac{a_{4}-a_{2}}{a_{1}+a_{2}}<1, a_{1}+a_{2} \neq 0, a_{1}+a_{2}+a_{3}>0 \text { and } 0 \leq a_{3}-a_{5}
$$

(4.40) $a_{1} d(T x, T y)+a_{2}[d(x, T x)+d(y, T y)]+a_{3}[d(y, T x)+d(x, T y)] \leq a_{4} d(x, y)+a_{5} d\left(x, T^{2} x\right)$ hold for all $x, y \in M$. Then, $T$ has at least one fixed point. 
Remark 4.6. As we discuss in Remark 4.5, we obtain the analog of Theorem 4.8 in the context of cone metric spaces. More precisely, again taking Example 1.6 into account, one can derive that Corollary 4.3 is also still fulfilled in the setting of cone metric space with normal cone (see e.g. [49]).

Theorem 4.9. Let $T$ be an orbitally continuous self-map on the T-orbitally complete b-metric space $(M, d)$. Suppose that there exists $\psi \in \Psi$ such that

$$
\frac{P(x, y)-Q(x, y)}{R(x, y)} \leq \psi(d(x, y))
$$

for all $x, y \in M$, where

$$
\begin{aligned}
& P(x, y)=\min \{d(T x, T y) d(x, y), d(x, T x) d(y, T y)\}, \\
& Q(x, y)=\min \{d(x, T x) d(x, T y), d(y, T y) d(T x, y)\}, \\
& R(x, y)=\min \{d(x, T x), d(y, T y)\} .
\end{aligned}
$$

with $R(x, y) \neq 0$. Then, for each $x_{0} \in M$ the sequence $\left\{T^{n} x_{0}\right\}_{n \in \mathbb{N}}$ converges to a fixed point of $T$.

Proof. As in the proof of Theorem 4.7, we shall construct an iterative sequence $\left\{x_{n}\right\}$, for an arbitrary initial value $x \in M$ :

$$
x_{0}:=x \text { and } x_{n}=T x_{n-1} \text { for all } n \in \mathbb{N} .
$$

As it is discussed in the proof of Theorem 4.7, we suppose

$$
x_{n} \neq x_{n-1} \text { for all } n \in \mathbb{N} \text {. }
$$

By substituting $x=x_{n-1}$ and $y=x_{n}$ in the inequality (4.41), we derive that

$$
\frac{P\left(x_{n-1}, x_{n}\right)-Q\left(x_{n-1}, x_{n}\right)}{R\left(x_{n-1}, x_{n}\right)} \leq \psi\left(d\left(x_{n-1}, x_{n}\right)\right),
$$

where

$$
\begin{aligned}
& P\left(x_{n-1}, x_{n}\right)=\min \left\{d\left(T x_{n-1}, T x_{n}\right) d\left(x_{n-1}, x_{n}\right), d\left(x_{n-1}, T x_{n-1}\right) d\left(x_{n}, T x_{n}\right)\right\}, \\
& Q\left(x_{n-1}, x_{n}\right)=\min \left\{d\left(x_{n-1}, T x_{n-1}\right) d\left(x_{n-1}, T x_{n}\right), d\left(x_{n}, T x_{n}\right) d\left(T x_{n-1}, x_{n}\right)\right\}, \\
& R\left(x_{n-1}, x_{n}\right)=\min \left\{d\left(x_{n-1}, T x_{n-1}\right), d\left(x_{n}, T x_{n}\right)\right\} .
\end{aligned}
$$

Due to axioms of $b$-metric space, we find that

$$
\frac{d\left(x_{n}, x_{n+1}\right) d\left(x_{n-1}, x_{n}\right)}{\min \left\{d\left(x_{n-1}, x_{n}\right), d\left(x_{n}, x_{n+1}\right)\right\}} \leq \psi\left(d\left(x_{n-1}, x_{n}\right)\right),
$$

If $R\left(x_{n-1}, x_{n}\right)=d\left(x_{n}, x_{n+1}\right)$, then, the inequality (4.45) turns into

$$
d\left(x_{n-1}, x_{n}\right) \leq \psi\left(d\left(x_{n-1}, x_{n}\right)\right)<d\left(x_{n-1}, x_{n}\right),
$$

which is a contraction, since $\psi(t)<t$ for all $t>0$. Accordingly, we deduce that

$$
d\left(x_{n}, x_{n+1}\right) \leq \psi\left(d\left(x_{n-1}, x_{n}\right)\right) .
$$

Applying Remark 1.1 recurrently, we find that

$$
d\left(x_{n}, x_{n+1}\right) \leq \psi\left(d\left(x_{n-1}, x_{n}\right)\right) \leq \psi^{2}\left(d\left(x_{n-2}, x_{n-1}\right)\right) \leq \cdots \leq \psi^{n}\left(d\left(x_{0}, x_{1}\right)\right) .
$$

By Lemma 1.2, we deduce that

$$
\lim _{n \rightarrow \infty} d\left(x_{n+1}, x_{n}\right)=0 .
$$

The rest of the proof is a verbatim repetition of the related lines in the proof of Theorem 4.7. 
Corollary 4.4. Let $T$ be an orbitally continuous self-map on the T-orbitally complete b-metric space $(M, d)$. Suppose that there exists $k \in[0,1)$ such that

$$
\frac{P(x, y)-Q(x, y)}{R(x, y)} \leq k d(x, y),
$$

for all $x, y \in M$, where

$$
\begin{aligned}
& P(x, y)=\min \{d(T x, T y) d(x, y), d(x, T x) d(y, T y)\} \\
& Q(x, y)=\min \{d(x, T x) d(x, T y), d(y, T y) d(T x, y)\}, \\
& R(x, y)=\min \{d(x, T x), d(y, T y)\} .
\end{aligned}
$$

with $R(x, y) \neq 0$. Then, for each $x_{0} \in M$ the sequence $\left\{T^{n} x_{0}\right\}_{n \in \mathbb{N}}$ converges to a fixed point of $T$.

Corollary 4.5. [Nonunique fixed point of Achari [1]] Let $T$ be an orbitally continuous self-map on the $T$-orbitally complete standard metric space $(M, d)$. Suppose that there exists $k \in[0,1)$ such that

$$
\frac{P(x, y)-Q(x, y)}{R(x, y)} \leq k d(x, y)
$$

for all $x, y \in M$, where

$$
\begin{aligned}
& P(x, y)=\min \{d(T x, T y) d(x, y), d(x, T x) d(y, T y)\} \\
& Q(x, y)=\min \{d(x, T x) d(x, T y), d(y, T y) d(T x, y)\}, \\
& R(x, y)=\min \{d(x, T x), d(y, T y)\} .
\end{aligned}
$$

with $R(x, y) \neq 0$. Then, for each $x_{0} \in M$ the sequence $\left\{T^{n} x_{0}\right\}_{n \in \mathbb{N}}$ converges to a fixed point of $T$.

Theorem 4.10. Let $T$ be an orbitally continuous self-map on the T-orbitally complete b-metric space $(M, d)$. Suppose that there exists $k \in[0,1)$ such that

$$
m(x, y)-n(x, y) \leq k d(x, T x) d(y, T y)
$$

for all $x, y \in M$, where

$$
\begin{aligned}
m(x, y) & =\min \left\{[d(T x, T y)]^{2}, d(x, y) d(T x, T y),[d(y, T y)]^{2}\right\}, \\
n(x, y) & =\min \{d(x, T x) d(y, T y), d(x, T y) d(y, T x)\}
\end{aligned}
$$

with $R(x, y) \neq 0$. Then, for each $x_{0} \in M$ the sequence $\left\{T^{n} x_{0}\right\}_{n \in \mathbb{N}}$ converges to a fixed point of $T$.

Proof. By following the lines in the proof of Theorem 4.7, we shall formulate an recursive sequence $\left\{x_{n}\right\}$, for an arbitrary initial value $x \in M$ :

$$
x_{0}:=x \text { and } x_{n}=T x_{n-1} \text { for all } n \in \mathbb{N} .
$$

Regarding the analysis in the proof of Theorem 4.7, we assume that

$$
x_{n} \neq x_{n-1} \text { for all } n \in \mathbb{N} \text {. }
$$

By replacing $x=x_{n-1}$ and $y=x_{n}$ in the inequality (4.52), we observe that

$$
m\left(x_{n-1}, x_{n}\right)-n\left(x_{n-1}, x_{n}\right) \leq k d\left(x_{n-1}, T x_{n-1}\right) d\left(x_{n}, T x_{n}\right),
$$

where

$$
\begin{aligned}
m\left(x_{n-1}, x_{n}\right) & =\min \left\{\left[d\left(T x_{n-1}, T x_{n}\right)\right]^{2}, d\left(x_{n-1}, x_{n}\right) d\left(T x_{n-1}, T x_{n}\right),\left[d\left(x_{n}, T x_{n}\right)\right]^{2}\right\}, \\
n\left(x_{n-1}, x_{n}\right) & =\min \left\{d\left(x_{n-1}, T x_{n-1}\right) d\left(x_{n}, T x_{n}\right), d\left(x_{n-1}, T x_{n}\right) d\left(x_{n}, T x_{n-1}\right)\right\} .
\end{aligned}
$$

By utilizing the above inequality, we get that

$$
m\left(x_{n-1}, x_{n}\right) \leq k d\left(x_{n-1}, x_{n}\right) d\left(x_{n}, x_{n+1}\right),
$$


where $m\left(x_{n-1}, x_{n}\right)=\min \left\{\left[d\left(x_{n}, x_{n+1}\right)\right]^{2}, d\left(x_{n-1}, x_{n}\right) d\left(x_{n}, x_{n+1}\right)\right\}$. Notice that the case $m\left(x_{n-1}, x_{n}\right)=$ $d\left(x_{n-1}, x_{n}\right) d\left(x_{n}, x_{n+1}\right)$ is impossible. Indeed, in this case, since $\psi(t)<t$ for all $t>0$, the inequality (4.56) turns into

$$
d\left(x_{n-1}, x_{n}\right) d\left(x_{n}, x_{n+1}\right) \leq k d\left(x_{n-1}, x_{n}\right) d\left(x_{n}, x_{n+1}\right)
$$

It is a contradiction since $k<1$. Appropriately, we infer that

$$
\left[d\left(x_{n}, x_{n+1}\right)\right]^{2} \leq k d\left(x_{n-1}, x_{n}\right) d\left(x_{n}, x_{n+1}\right)
$$

which is equivalent to

$$
d\left(x_{n}, x_{n+1}\right) \leq k d\left(x_{n-1}, x_{n}\right) .
$$

Recurrently, we find that

$$
d\left(x_{n}, x_{n+1}\right) \leq k^{n} d\left(x_{0}, x_{1}\right) .
$$

The rest of the proof is a verbatim repetition of the related lines in the proof of Theorem 4.8.

Theorem 4.8 is still valid in the context of standard metric space.

Corollary 4.6. [Nonunique fixed point of Pachpatte [65]] Let $T$ be an orbitally continuous self-map on the $T$-orbitally complete standard metric space $(M, d)$. Suppose that there exists $k \in[0,1)$ such that

$$
m(x, y)-n(x, y) \leq k d(x, T x) d(y, T y)
$$

for all $x, y \in M$, where

$$
\begin{aligned}
m(x, y) & =\min \left\{[d(T x, T y)]^{2}, d(x, y) d(T x, T y),[d(y, T y)]^{2}\right\}, \\
n(x, y) & =\min \{d(x, T x) d(y, T y), d(x, T y) d(y, T x)\}
\end{aligned}
$$

with $R(x, y) \neq 0$. Then, for each $x_{0} \in M$ the sequence $\left\{T^{n} x_{0}\right\}_{n \in \mathbb{N}}$ converges to a fixed point of $T$.

Remark 4.7. One can deduce the analog of Theorem 4.10 in the context of cone metric spaces as it mentioned in Remark 4.5.

\section{ON GENERALIZED $\alpha-\psi$-GERAGHTY CONTRACTIVE MAPPING}

Now, we are ready to state and prove our main results. Let $\Psi$ be set of all increasing and continuous functions $\psi:[0, \infty) \rightarrow[0, \infty)$ with $\psi^{-1}(\{0\})=\{0\}$. Let $\mathcal{F}$ be the family of all nondecreasing functions $\beta:[0, \infty) \rightarrow\left[0, \frac{1}{s}\right)$ which satisfy the condition

$$
\lim _{n \rightarrow \infty} \beta\left(t_{n}\right)=\frac{1}{s} \text { implies } \lim _{n \rightarrow \infty} t_{n}=0,
$$

for some $s \geq 1$.

Definition 5.15. Let $(M, d)$ be a b-metric space and $T: M \rightarrow M$ be a self-map. We say that $T$ is a generalized $\alpha-\psi$-Geraghty contractive mapping whenever there exist $\alpha: M \times M \rightarrow[0, \infty)$ and some $L \geq 0$ such that for

$$
E(x, y)=\max \left\{d(x, y), d(x, T x), d(y, T y), \frac{d(x, T y)+d(y, T x)}{2 s}\right\}
$$

$$
\text { and } N(x, y)=\min \{d(x, T x), d(y, T x)\},
$$

we have

$$
\alpha(x, y) \psi\left(s^{3} d(T x, T y)\right) \leq \beta(\psi(E(x, y))) \psi(E(x, y))+L \phi(N(x, y)),
$$

for all $x, y \in M$, where $\beta \in \mathcal{F}$ and $\psi, \phi \in \Psi$. 
Remark 5.8. Since the functions belonging to $\mathcal{F}$ are strictly smaller than $\frac{1}{s}$, the expression $\beta(\psi(E(x, y)))$ in (5.65) can be estimated as

$$
\beta(\psi(E(x, y)))<\frac{1}{s} \text { for any } x, y \in M \text { with } x \neq y .
$$

Theorem 5.11. Let $(M, d)$ be a complete b-metric space and $T: M \rightarrow M$ be a generalized $\alpha-\psi$ Geraghty contractive mapping such that

(i) $T$ is triangular $\alpha$-orbital admissible;

(ii) there exists $x_{0} \in M$ such that $\alpha\left(x_{0}, T x_{0}\right) \geq 1$;

(iii) $T$ is continuous.

Then $T$ has a fixed point.

Proof. Let $x_{0} \in M$ be such that $\alpha\left(x_{0}, T x_{0}\right) \geq 1$. We construct an iterative sequence $\left\{x_{n}\right\}$ such that

$$
x_{n+1}=T x_{n}, \quad n \in \mathbb{N}_{0} .
$$

If there exists an $n_{0}$ such that $T x_{n_{0}}=x_{n_{0}}$ for some $n_{0}$, then $x_{n_{0}}$ is a fixed point of $T$ which completes the proof. Thus, without loss of generality, we assume that

$$
x_{n} \neq x_{n+1} \text { for all } n \in \mathbb{N}_{0} \text {. }
$$

The mapping $T$ is triangular $\alpha$-orbital admissible, by Lemma 2.3, we have

$$
\alpha\left(x_{n}, x_{n+1}\right) \geq 1, \text { for all } n \in \mathbb{N}_{0} .
$$

By taking $x=x_{n-1}$ and $y=x_{n}$ in the inequality (5.65) together with the inequality (5.67) and regarding that $\psi$ is an increasing function, we obtain

$$
\begin{aligned}
\psi\left(d\left(x_{n}, x_{n+1}\right)\right) & =\psi\left(d\left(T x_{n-1}, T x_{n}\right)\right) \leq \alpha\left(x_{n-1}, x_{n}\right) \psi\left(s^{3} d\left(T x_{n-1}, T x_{n}\right)\right) \\
& \leq \beta\left(\psi\left(M\left(x_{n-1}, x_{n}\right)\right)\right) \psi\left(M\left(x_{n-1}, x_{n}\right)\right)+L \phi\left(N\left(x_{n-1}, x_{n}\right)\right),
\end{aligned}
$$

for all $n \in \mathbb{N}$, where

$$
\begin{aligned}
M\left(x_{n-1}, x_{n}\right) & =\max \left\{d\left(x_{n-1}, x_{n}\right), d\left(x_{n-1}, T x_{n-1}\right), d\left(x_{n}, T x_{n}\right), \frac{d\left(x_{n-1}, T x_{n}\right)+d\left(x_{n}, T x_{n-1}\right)}{2 s}\right\} \\
& =\max \left\{d\left(x_{n-1}, x_{n}\right), d\left(x_{n-1}, x_{n}\right), d\left(x_{n}, x_{n+1}\right), \frac{d\left(x_{n-1}, x_{n+1}\right)+d\left(x_{n}, x_{n}\right)}{2 s}\right\} \\
& =\max \left\{d\left(x_{n-1}, x_{n}\right), d\left(x_{n}, x_{n+1}\right), \frac{d\left(x_{n-1}, x_{n+1}\right)}{2 s}\right\}
\end{aligned}
$$

and

$$
\begin{aligned}
N\left(x_{n-1}, x_{n}\right) & =\min \left\{d\left(x_{n-1}, T x_{n-1}\right), d\left(x_{n}, T x_{n-1}\right)\right\} \\
& =\min \left\{d\left(x_{n-1}, x_{n}\right), d\left(x_{n}, x_{n}\right)\right\}=0 .
\end{aligned}
$$

Since

$$
\frac{d\left(x_{n-1}, x_{n+1}\right)}{2 s} \leq \frac{s\left[d\left(x_{n-1}, x_{n}\right)+d\left(x_{n}, x_{n+1}\right)\right]}{2 s} \leq \max \left\{d\left(x_{n-1}, x_{n}\right), d\left(x_{n}, x_{n+1}\right)\right\},
$$

then we get

$$
M\left(x_{n-1}, x_{n}\right) \leq \max \left\{d\left(x_{n-1}, x_{n}\right), d\left(x_{n}, x_{n+1}\right)\right\} .
$$

Taking (5.70) and (5.69) into account, (5.68) yields that

$$
\begin{aligned}
& \psi\left(d\left(x_{n}, x_{n+1}\right)\right) \leq \psi\left(s^{3} d\left(x_{n}, x_{n+1}\right)\right) \leq \alpha\left(x_{n-1}, x_{n}\right) \psi\left(s^{3} d\left(x_{n}, x_{n+1}\right)\right) \\
& \leq \beta\left(\psi\left(M\left(x_{n-1}, x_{n}\right)\right) \psi\left(\max \left\{d\left(x_{n-1}, x_{n}\right), d\left(x_{n}, x_{n+1}\right)\right\}\right) .\right.
\end{aligned}
$$


If for some $n \in \mathbb{N}$, we have $\max \left\{d\left(x_{n-1}, x_{n}\right), d\left(x_{n}, x_{n+1}\right)\right\}=d\left(x_{n}, x_{n+1}\right)$, then by (5.71) and Remark 5.8, we get

$$
\psi\left(d\left(x_{n}, x_{n+1}\right)\right) \leq \beta\left(\psi ( M ( x _ { n - 1 } , x _ { n } ) ) \psi \left(d\left(x_{n}, x_{n+1}\right)<\frac{1}{s} \psi\left(d\left(x_{n}, x_{n+1}\right)<\psi\left(d\left(x_{n}, x_{n+1}\right),\right.\right.\right.\right.
$$

which is a contradiction. Thus, from (5.71) we conclude that

$$
\psi\left(d\left(x_{n}, x_{n+1}\right)\right) \leq \beta\left(\psi\left(M\left(x_{n-1}, x_{n}\right)\right)\right) \psi\left(d\left(x_{n-1}, x_{n}\right)\right)<\frac{1}{s} \psi\left(d\left(x_{n-1}, x_{n}\right)\right)<\psi\left(d\left(x_{n-1}, x_{n}\right)\right),
$$

for all $n \in \mathbb{N}$. Hence $\left\{\psi\left(d\left(x_{n}, x_{n+1}\right)\right)\right\}$ is a non-negative decreasing sequence. Since $\psi$ is increasing, so the sequence $\left\{d\left(x_{n}, x_{n+1}\right)\right\}$ is non-increasing. Consequently, there exists $\delta \geq 0$ such that $\lim _{n \rightarrow \infty} d\left(x_{n}, x_{n+1}\right)=\delta$. We claim that $\delta=0$. Suppose, on the contrary that

$$
\lim _{n \rightarrow \infty} d\left(x_{n}, x_{n+1}\right)=\delta>0 .
$$

Since $s \geq 1$, the inequality (5.73) can be estimated as

$$
\frac{1}{s} \psi\left(d\left(x_{n}, x_{n+1}\right)\right) \leq \psi\left(d\left(x_{n}, x_{n+1}\right)\right) \leq \beta\left(\psi\left(M\left(x_{n-1}, x_{n}\right)\right)\right) \psi\left(d\left(x_{n-1}, x_{n}\right)\right) .
$$

Regarding (5.66), the inequality (5.75) implies that

$$
\frac{1}{s} \frac{\psi\left(d\left(x_{n}, x_{n+1}\right)\right)}{\psi\left(d\left(x_{n-1}, x_{n}\right)\right)} \leq \beta\left(\psi\left(M\left(x_{n-1}, x_{n}\right)\right)\right)<\frac{1}{s} .
$$

It yields that $\lim _{n \rightarrow \infty} \beta\left(\psi\left(M\left(x_{n-1}, x_{n}\right)\right)\right)=\frac{1}{s}$. Since $\beta \in \mathcal{F}$, then $\lim _{n \rightarrow \infty} \psi\left(M\left(x_{n-1}, x_{n}\right)\right)=0$. We deduce that

$$
\lim _{n \rightarrow \infty} \psi\left(d\left(x_{n}, x_{n+1}\right)\right)=0 .
$$

Thus, regarding the fact that $d\left(x_{n}, x_{n+1}\right) \rightarrow \delta$ and the continuity of $\psi$, we derive that $\psi(\delta)=0$. Since $\psi^{-1}(\{0\})=\{0\}$, so $\delta=0$, which is a contradiction. Thus, we have

$$
\lim _{n \rightarrow \infty} d\left(x_{n}, x_{n+1}\right)=0 .
$$

Now, we claim that

$$
\lim _{m, n \rightarrow \infty} d\left(x_{n}, x_{m}\right)=0 .
$$

Assume on the contrary that exist $\varepsilon>0$ and subsequences $\left\{x_{m_{i}}\right\},\left\{x_{n_{i}}\right\}$ of $\left\{x_{n}\right\}$ with $n_{i}>m_{i} \geq$ $i$ such that

$$
d\left(x_{m_{i}}, x_{n_{i}}\right) \geq \varepsilon
$$

Additionally, corresponding to $m_{i}$, we may choose $n_{i}$ such that it is the smallest integer satisfying (5.77) and $n_{i}>m_{i} \geq i$. Thus, we have

$$
d\left(x_{m_{i}}, x_{n_{i}-1}\right)<\varepsilon .
$$

From (5.77) and the triangle inequality, we obtain

$$
\begin{aligned}
\varepsilon \leq d\left(x_{n_{i}}, x_{m_{i}}\right) & \leq s d\left(x_{n_{i}}, x_{n_{i+1}}\right)+s d\left(x_{n_{i+1}}, x_{m_{i}}\right) \\
& \leq s d\left(x_{n_{i}}, x_{n_{i+1}}\right)+s^{2} d\left(x_{n_{i+1}}, x_{m_{i+1}}\right)+s^{2} d\left(x_{m_{i+1}}, x_{m_{i}}\right) .
\end{aligned}
$$

Letting $i \rightarrow \infty$ and regarding (5.76), the inequality (5.79) yields that

$$
\frac{\varepsilon}{s^{2}} \leq \limsup _{i \rightarrow \infty} d\left(x_{n_{i+1}}, x_{m_{i+1}}\right) \text {. }
$$


By Lemma 2.3, recall that

$$
\alpha\left(x_{m_{i}}, x_{n_{i}}\right) \geq 1
$$

Consequently, by (5.65) we have

$$
\begin{aligned}
\psi\left(d\left(x_{n_{i+1}}, x_{m_{i+1}}\right)\right) & =\psi\left(d\left(T x_{n_{i}}, T x_{m_{i}}\right)\right) \\
& \leq \psi\left(s^{3} d\left(T x_{n_{i}}, T x_{m_{i}}\right)\right) \leq \alpha\left(x_{m_{i}}, x_{n_{i}}\right) \psi\left(s^{3} d\left(T x_{n_{i}}, T x_{m_{i}}\right)\right) \\
& \leq \beta\left(\psi\left(M\left(x_{n_{i}}, x_{m_{i}}\right)\right) \psi\left(M\left(x_{n_{i}}, x_{m_{i}}\right)\right)+L \phi\left(d\left(x_{m_{i}}, T x_{n_{i}}\right)\right)\right),
\end{aligned}
$$

where

$$
\begin{aligned}
M\left(x_{n_{i}}, x_{m_{i}}\right) & =\max \left\{d\left(x_{n_{i}}, x_{m_{i}}\right), d\left(x_{n_{i}}, T x_{n_{i}}\right), d\left(x_{m_{i}}, T x_{m_{i}}\right), \frac{d\left(x_{n_{i}}, T x_{m_{i}}\right)+d\left(x_{m_{i}}, T x_{n_{i}}\right)}{2 s}\right\} \\
& =\max \left\{d\left(x_{n_{i}}, x_{m_{i}}\right), d\left(x_{n_{i}}, x_{n_{i+1}}\right), d\left(x_{m_{i}}, x_{m_{i+1}}\right), \frac{d\left(x_{n_{i}}, x_{m_{i+1}}\right)+d\left(x_{m_{i}}, x_{n_{i+1}}\right)}{2 s}\right\},
\end{aligned}
$$

and

$$
N\left(x_{n_{i}}, x_{m_{i}}\right)=\min \left\{d\left(x_{n_{i}}, T x_{n_{i}}\right), d\left(x_{m_{i}}, T x_{n_{i}}\right)\right\}=\min \left\{d\left(x_{n_{i}}, x_{n_{i}+1}\right), d\left(x_{m_{i}}, x_{n_{i}+1}\right)\right\} .
$$

Notice that

$$
\frac{d\left(x_{n_{i}}, x_{m_{i+1}}\right)+d\left(x_{m_{i}}, x_{n_{i+1}}\right)}{2 s} \leq \frac{s\left[d\left(x_{n_{i}}, x_{m_{i}}\right)+d\left(x_{m_{i}}, x_{m_{i+1}}\right)\right]+s\left[d\left(x_{m_{i}}, x_{n_{i}}\right)+d\left(x_{n_{i}}, x_{n_{i+1}}\right)\right]}{2 s}
$$

and

$$
d\left(x_{n_{i}}, x_{m_{i}}\right) \leq s\left[d\left(x_{n_{i}}, x_{n_{i}-1}\right)+d\left(x_{n_{i}-1}, x_{m_{i}}\right)\right]<s d\left(x_{n_{i}}, x_{n_{i}-1}\right)+s \varepsilon .
$$

Taking (5.78), (5.84) and (5.85) into account, we find that

$$
\limsup _{i \rightarrow \infty} M\left(x_{n_{i}}, x_{m_{i}}\right) \leq s \varepsilon, \text { and }
$$

$$
\lim _{i \rightarrow \infty} N\left(x_{n_{i}}, x_{m_{i}}\right)=0 .
$$

By taking the upper limit as $i \rightarrow \infty$ and regarding the condition (T4) together with the expressions (5.80), (5.86) and (5.87), the inequality (5.82) becomes

$$
\begin{aligned}
\frac{1}{s} \psi(s \varepsilon) \leq \psi(s \varepsilon) & \leq \limsup _{i \rightarrow \infty} \psi\left(s^{3} d\left(x_{n_{i+1}}, x_{m_{i+1}}\right)\right) \\
& \left.\leq \limsup _{i \rightarrow \infty} \alpha\left(x_{m_{i}}, x_{n_{i}}\right)\right) \psi\left(s^{3} d\left(x_{n_{i+1}}, x_{m_{i+1}}\right)\right) \\
& =\limsup _{i \rightarrow \infty} \alpha\left(x_{m_{i}}, x_{n_{i}}\right) \psi\left(s^{3} d\left(T x_{n_{i}}, T x_{m_{i}}\right)\right) \\
& \leq \limsup _{i \rightarrow \infty}\left[\beta\left(\psi\left(M\left(x_{n_{i}}, x_{m_{i}}\right)\right) \psi\left(M\left(x_{n_{i}}, x_{m_{i}}\right)\right)+L \phi\left(N\left(d\left(x_{n_{i}}, x_{m_{i}}\right)\right)\right)\right]\right. \\
& \leq \psi(s \varepsilon) \limsup _{i \rightarrow \infty} \beta\left(\psi\left(M\left(x_{n_{i}}, x_{m_{i}}\right)\right)\right) \\
& \leq \frac{1}{s} \psi(s \varepsilon) .
\end{aligned}
$$

Then $\limsup _{i \rightarrow \infty} \beta\left(\psi\left(M\left(x_{n_{i}}, x_{m_{i}}\right)\right)\right)=\frac{1}{s}$. Due to the fact $\beta \in \mathcal{F}$, we have

$$
\limsup _{i \rightarrow \infty} \psi\left(M\left(x_{n_{i}}, x_{m_{i}}\right)\right)=0 \text {. }
$$


Thus, we conclude that

$$
\lim _{i \rightarrow \infty} \psi\left(d\left(x_{n_{i}}, x_{m_{i}}\right)\right)=0 .
$$

Therefore, by continuity of $\psi$ and the fact that $\psi^{-1}(\{0\})=\{0\}$, so

$$
\lim _{i \rightarrow \infty} d\left(x_{n_{i}}, x_{m_{i}}\right)=0,
$$

which is a contradiction with respect to (5.77). We deduce that $\left\{x_{n}\right\}$ is a Cauchy sequence in $(M, d)$. Since $(M, d)$ is a complete $b$-metric space, there exists $x^{*} \in M$ such that $\lim _{n \rightarrow \infty} x_{n}=x^{*}$. The mapping $T$ is continuous and it is obvious that $T x^{*}=x^{*}$. $X$.

We replace the continuity of the mapping $T$ in the above theorem by a suitable condition on

Theorem 5.12. Let $(M, d)$ be a complete b-metric space and $T: M \rightarrow M$ be a generalized $\alpha-\psi$ Geraghty contractive mapping such that

(i) $T$ is triangular $\alpha$-orbital admissible;

(ii) there exists $x_{0} \in M$ such that $\alpha\left(x_{0}, T x_{0}\right) \geq 1$;

(iii) $X$ is $\alpha$-regular.

Then $T$ has a fixed point.

Proof. Following the lines in the proof of Theorem 5.11, we conclude that $\lim _{n \rightarrow \infty} x_{n}=x^{*}$. If $X$ is $\alpha$-regular, then since $\alpha\left(x_{n}, x_{n+1}\right) \geq 1$, so there exists a subsequence $\left\{x_{n_{k}}\right\}$ of $\left\{x_{n}\right\}$ such that

$$
\alpha\left(x_{n_{k}}, x^{*}\right) \geq 1
$$

for all $k$. By triangular inequality

$$
\begin{aligned}
d\left(x^{*}, T x^{*}\right) & \leq s d\left(x^{*}, x_{n_{k}+1}\right)+s d\left(x_{n_{k}+1}, T x^{*}\right) \\
& =s d\left(x^{*}, x_{n_{k}+1}\right)+\operatorname{sd}\left(T x_{n_{k}}, T x^{*}\right) .
\end{aligned}
$$

Letting $k$ tends to infinity

$$
d\left(x^{*}, T x^{*}\right) \leq \liminf _{k \rightarrow \infty} s d\left(T x_{n_{k}}, T x^{*}\right) .
$$

Having $\psi \in \Psi$, (5.89) and (5.90), so

$$
\begin{aligned}
\psi\left(s^{2} d\left(x^{*}, T x^{*}\right)\right) & \leq \lim _{k \rightarrow \infty} \psi\left(s^{3} d\left(T x_{n_{k}}, T x^{*}\right)\right) \leq \lim _{k \rightarrow \infty} \alpha\left(x_{n_{k+1}}, x^{*}\right) \psi\left(s^{3} d\left(T x_{n_{k}}, T x^{*}\right)\right) \\
& \leq \lim _{k \rightarrow \infty}\left[\beta\left(\psi\left(M\left(x_{n_{k}}, x^{*}\right)\right)\right) \psi\left(M\left(x_{n_{k}}, x^{*}\right)\right)+L \phi\left(N\left(x_{n_{k}}, x^{*}\right)\right)\right] .
\end{aligned}
$$

We have

$$
\begin{aligned}
M\left(x_{n_{k}}, x^{*}\right) & =\max \left\{d\left(x_{n_{k}}, x^{*}\right), d\left(x_{n_{k}}, T x_{n_{k}}\right), d\left(x^{*}, T x^{*}\right), \frac{d\left(x_{n_{k}}, T x^{*}\right)+d\left(x^{*}, T x_{n_{k}}\right)}{2 s}\right\} \\
& =\max \left\{d\left(x_{n_{k}}, x^{*}\right), d\left(x_{n_{k}}, x_{n_{k+1}}\right), d\left(x^{*}, T x^{*}\right), \frac{d\left(x_{n_{k}}, T x^{*}\right)+d\left(x^{*}, x_{n_{k+1}}\right)}{2 s}\right\},
\end{aligned}
$$

and

$$
\begin{aligned}
N\left(x_{n_{k}}, x^{*}\right) & =\min \left\{d\left(x_{n_{k}}, T x_{n_{k}}\right), d\left(x^{*}, T x_{n_{k}}\right)\right\} \\
& =\min \left\{d\left(x_{n_{k}}, x_{n_{k+1}}\right), d\left(x^{*}, x_{n_{k+1}}\right)\right\} .
\end{aligned}
$$

Recall that

$$
\frac{d\left(x_{n_{k}}, T x^{*}\right)+d\left(x^{*}, x_{n_{k+1}}\right)}{2 s} \leq \frac{s d\left(x_{n_{k}}, x^{*}\right)+s d\left(x^{*}, T x^{*}\right)+d\left(x^{*}, x_{n_{k+1}}\right)}{2 s} .
$$


Then, by (5.76), we get that

$$
\limsup _{k \rightarrow \infty} \frac{d\left(x_{n_{k}}, T x^{*}\right)+d\left(x^{*}, x_{n_{k+1}}\right)}{2 s} \leq \frac{d\left(x^{*}, T x^{*}\right)}{2} .
$$

When $k$ tends to infinity, we deduce

$$
\lim _{k \rightarrow \infty} M\left(x_{n_{k}}, x^{*}\right)=d\left(x^{*}, T x^{*}\right),
$$

and

$$
\lim _{k \rightarrow \infty} N\left(x_{n_{k}}, x^{*}\right)=0
$$

Since $\beta\left(\psi\left(M\left(x_{n_{k}}, x^{*}\right)\right)\right) \leq \frac{1}{s}, \forall k \in \mathbb{N}$ so by (5.91)

$$
\psi\left(s^{2} d\left(x^{*}, T x^{*}\right)\right) \leq \frac{1}{s} \psi\left(d\left(x^{*}, T x^{*}\right)\right) \leq \psi\left(d\left(x^{*}, T x^{*}\right)\right) .
$$

Since $\psi \in \Psi$, so the above holds unless $d\left(x^{*}, T x^{*}\right)=0$, that is, $T x^{*}=x^{*}$ and $x^{*}$ is a fixed point of $T$.

For the uniqueness of a fixed point of a generalized $\alpha-\psi$ contractive mapping, we will consider the following hypothesis.

$(\mathrm{H})$ For all $x, y \in \operatorname{Fix}(T)$, either $\alpha(x, y) \geq 1$ or $\alpha(y, x) \geq 1$.

Here, $\operatorname{Fix}(T)$ denotes the set of fixed points of $T$.

Theorem 5.13. Adding condition $(H)$ to hypotheses of Theorem 5.11 (respectively, Theorem 5.12 ), we obtain uniqueness of the fixed point of $T$.

Proof. Suppose that $x^{*}$ and $y^{*}$ are two fixed points of $T$. Then we have, it is obvious that $M\left(x^{*}, y^{*}\right)=d\left(x^{*}, y^{*}\right)$ and $N\left(x^{*}, y^{*}\right)=0$. So

$$
\begin{aligned}
& \psi\left(d\left(x^{*}, y^{*}\right)\right) \leq \psi\left(s^{3} d\left(T x^{*}, T y^{*}\right)\right) \\
& \leq \alpha\left(x^{*}, y^{*}\right) \psi\left(s^{3} d\left(T x^{*}, T y^{*}\right)\right) \\
& \leq \beta\left(\psi\left(M\left(x^{*}, y^{*}\right)\right) \psi\left(M\left(x^{*}, y^{*}\right)\right)+L \phi\left(N\left(x^{*}, y^{*}\right)\right)\right. \\
& <\frac{1}{s} \psi\left(d\left(x^{*}, y^{*}\right)\right) \leq \psi\left(d\left(x^{*}, y^{*}\right)\right),
\end{aligned}
$$

which is contradiction.

Definition 5.16. Let $(M, d)$ be a b-metric space and $T: M \rightarrow M$ be a self-map. We say that $T$ is a generalized $\alpha-\psi$-Geraghty contractive mapping of type $(B)$ whenever there exists $\alpha: M \times M \rightarrow[0, \infty)$ such that for

$$
E(x, y)=\max \left\{d(x, y), d(x, T x), d(y, T y), \frac{d(x, T y)+d(y, T x)}{2 s}\right\}
$$

we have

$$
\alpha(x, y) \psi\left(s^{3} d(T x, T y)\right) \leq \beta(\psi(E(x, y))) \psi(E(x, y))
$$

for all $x, y \in M$, where $\beta \in \mathcal{F}$ and $\psi \in \Psi$.

By verbatim of the proofs of Theorem 5.11, Theorem 5.12 and Theorem 5.13, we get the following results: 
Theorem 5.14. Let $(M, d)$ be a complete b-metric space and $T: M \rightarrow M$ be a generalized $\alpha-\psi$ Geraghty contractive mapping of type $(B)$ such that

(i) $T$ is triangular $\alpha$-orbital admissible;

(ii) there exists $x_{0} \in M$ such that $\alpha\left(x_{0}, T x_{0}\right) \geq 1$;

(iii) either $T$ is continuous or $X$ is $\alpha$-regular.

Then $T$ has a fixed point.

Theorem 5.15. Adding condition $(H)$ to hypotheses of Theorem 5.14, we obtain uniqueness of the fixed point of $T$.

Example 5.9. Let $X$ be the set of Lebesgue measurable functions on $[0,1]$ such that

$$
\int_{0}^{1}|x(t)| d t<1
$$

Define $d: M \times M \rightarrow[0, \infty)$ by

$$
d(x, y)=\left(\int_{0}^{1}|x(t)-y(t)| d t\right)^{2} .
$$

Then, $d$ is a b-metric on $X$ with $s=2$.

The operator $T: M \rightarrow M$ is defined by

$$
T x(t)=\frac{1}{4} \ln (1+|x(t)|) .
$$

Consider the mappings $\alpha: M \times M \rightarrow[0, \infty), \beta:[0, \infty) \rightarrow\left[0, \frac{1}{2}\right)$ and $\psi:[0, \infty) \rightarrow[0, \infty)$ defined by

$$
\begin{aligned}
\alpha(x, y) & =\left\{\begin{array}{l}
1 \text { if } x(t) \geq y(t), \forall t \in[0,1], \\
0 \text { otherwise. }
\end{array}\right. \\
\psi(t) & =t \quad \text { and } \quad \beta(t)=\frac{(\ln (1+\sqrt{t}))^{2}}{2 t} .
\end{aligned}
$$

Evidently, $\psi \in \Psi$ and $\beta \in \mathcal{F}$. Moreover, $T$ is a triangular $\alpha$-orbital admissible mapping and $\alpha(1, T 1) \geq$ 1.

Now, we shall prove that $T$ is a generalized $\alpha-\psi$-Geraghty contractive mapping. In fact, for all $t \in[0,1]$, we have

$$
\begin{aligned}
& \sqrt{\alpha(x(t), y(t)) \psi\left(s^{3} d(T x(t), T y(t))\right)} \leq \sqrt{2^{3}\left(\int_{0}^{1}|T x(t)-T y(t)| d t\right)^{2}} \\
& \leq 2 \sqrt{2} \int_{0}^{1}\left|\frac{1}{4} \ln (1+|x(t)|)-\frac{1}{4} \ln (1+|y(t)|)\right| d t \\
& =\frac{1}{\sqrt{2}} \int_{0}^{1}\left|\ln \left(\frac{1+|x(t)|}{1+|y(t)|}\right)\right| d t \\
& =\frac{1}{\sqrt{2}} \int_{0}^{1}\left|\ln \left(1+\frac{|x(t)|-|y(t)|}{1+|y(t)|}\right)\right| d t \\
& \leq \frac{1}{\sqrt{2}} \int_{0}^{1}|\ln (1+|x(t)|-|y(t)|)| d t
\end{aligned}
$$


By Lemma 8.4 (given in Appendix), we get

$$
\int_{0}^{1}|\ln (1+|x(t)|-|y(t)|)| d t \leq \ln \left(\int_{0}^{1}(1+|x(t)-y(t)|) d t\right)=\ln \left(1+\int_{0}^{1}|x(t)-y(t)| d t\right) .
$$

Therefore

$$
\begin{aligned}
\sqrt{\alpha(x(t), y(t)) \psi\left(s^{3} d(T x(t), T y(t))\right)} & \leq \frac{1}{\sqrt{2}} \ln \left(1+\int_{0}^{1}|x(t)-y(t)| d t\right) \\
& \leq \frac{1}{\sqrt{2}} \ln (1+\sqrt{d(x, y)})
\end{aligned}
$$

So, we obtain

$$
\begin{aligned}
& \alpha(x(t), y(t)) \psi\left(s^{3} d(T x(t), T y(t))\right) \leq \frac{1}{2}(\ln (1+\sqrt{d(x, y)}))^{2} \\
& \leq \frac{1}{2}(\ln (1+\sqrt{E(x, y)}))^{2} \\
& =\frac{(\ln (1+\sqrt{E(x, y)}))^{2}}{2 E(x, y)} E(x, y) \\
& =\beta(\psi(E(x, y))) \psi(E(x, y)) .
\end{aligned}
$$

Thus, by Theorem 5.14, we see that $T$ has a fixed point.

\section{CONSEQUENCES}

In this section, we shall demonstrate that several existing results in the literature can be easily concluded from Theorem 5.13.

6.1. Standard fixed point theorems in $b$-metric. By taking $\alpha(x, y)=1$ in Theorem 5.13, for all $x, y \in M$, we obtain immediately the following fixed point theorem.

Corollary 6.7. Let $(M, d)$ be a complete b-metric space with $s \geq 1$ and $T: M \rightarrow M$ be a mapping on $X$. If there exists $L \geq 0$ such that for all $x, y \in M$,

$$
\psi\left(s^{3} d(T x, T y)\right) \leq \beta(\psi(E(x, y))) \psi(E(x, y))+L \phi(N(x, y)),
$$

where $\beta \in \mathcal{F}, \psi, \phi \in \Psi$ and

$$
\begin{gathered}
E(x, y)=\max \left\{d(x, y), d(x, T x), d(y, T y), \frac{d(x, T y)+d(y, T x)}{2 s}\right\}, \\
\text { and } N(x, y)=\min \{d(x, T x), d(y, T x)\},
\end{gathered}
$$

then $T$ has a unique fixed point.

By taking $\alpha(x, y)=1$ in Theorem 5.15, for all $x, y \in M$, we obtain immediately the following fixed point result.

Corollary 6.8. Let $(M, d)$ be a complete b-metric space with $s \geq 1$ and $T: M \rightarrow M$ be a mapping on $X$ such that for all $x, y \in M$,

$$
\psi\left(s^{3} d(T x, T y)\right) \leq \beta(\psi(E(x, y))) \psi(E(x, y))
$$

where $\beta \in \mathcal{F}, \psi \in \Psi$ and

$$
E(x, y)=\max \left\{d(x, y), d(x, T x), d(y, T y), \frac{d(x, T y)+d(y, T x)}{2 s}\right\}
$$


Then $T$ has a unique fixed point.

If we put $\alpha(x, y)=1, \forall x, y \in M, L=0$ and $\psi(t)=t$ in Theorem 5.13, we may state the following result.

Corollary 6.9. Let $(M, d)$ be a complete $b$-metric space with $s \geq 1$ and $T: M \rightarrow M$ be a mapping on $X$ such that for all $x, y \in M$,

$$
s^{3} d(T x, T y) \leq \beta(E(x, y)) E(x, y)
$$

where $\beta \in \mathcal{F}$ and

$$
E(x, y)=\max \left\{d(x, y), d(x, T x), d(y, T y), \frac{d(x, T y)+d(y, T x)}{2 s}\right\} .
$$

Then, $T$ has a unique fixed point.

If we take $s=1$ and $\beta(t)=\frac{1}{t+1}$ for $t>0$ in Corollary 6.9, we deduce the following result.

Corollary 6.10. Let $(M, d)$ be a complete metric space and $T: M \rightarrow M$ be a mapping on $X$ such that for all $x, y \in M$,

Then $T$ has a unique fixed point.

$$
d(T x, T y) \leq \frac{E(x, y)}{1+E(x, y)} .
$$

6.2. Fixed point theorems on $b$-metric spaces endowed with a partial order. On the last decade, several exciting developments have been reported in the field of existence of fixed point on metric spaces endowed with partial orders see e.g. [64, 69, 81]. In this section, from Theorem 5.13 (and also from Theorem 5.15), we shall easily conclude some fixed point results on a $b$-metric space endowed with a partial order. First of all, we recall some basic concepts:

Definition 6.17. Let $(M, \preceq)$ be a partially ordered set and $T: M \rightarrow M$ be a given mapping. We say that $T$ is nondecreasing with respect to $\preceq$ if

$$
x, y \in M, x \preceq y \Longrightarrow T x \preceq T y .
$$

Definition 6.18. Let $(M, \preceq)$ be a partially ordered set. A sequence $\left\{x_{n}\right\} \subset X$ is said to be nondecreasing with respect to $\preceq$ if $x_{n} \preceq x_{n+1}$ for all $n$.

Definition 6.19. Let $(M, \preceq)$ be a partially ordered set and $d$ be a b-metric on $X$. We say that $(M, \preceq, d)$ is regular if for every nondecreasing sequence $\left\{x_{n}\right\} \subset X$ such that $x_{n} \rightarrow x \in M$ as $n \rightarrow \infty$, there exists a subsequence $\left\{x_{n(k)}\right\}$ of $\left\{x_{n}\right\}$ such that $x_{n(k)} \preceq x$ for all $k$.

We have the following result.

Corollary 6.11. Let $(M, \preceq)$ be a partially ordered set and $d$ be a b-metric on $X$ such that $(M, d)$ is complete. Let $T: M \rightarrow M$ be a nondecreasing mapping with respect to $\preceq$. Suppose that there exist functions $\beta \in \mathcal{F}, \psi \in \Psi$ such that

$$
\psi\left(s^{3} d(T x, T y)\right) \leq \beta(\psi(E(x, y))) \psi(E(x, y))
$$

and

$$
E(x, y)=\max \left\{d(x, y), d(x, T x), d(y, T y), \frac{d(x, T y)+d(y, T x)}{2 s}\right\},
$$

for all $x, y \in M$ with $x \succeq y$. Suppose also that the following conditions hold:

(i) there exists $x_{0} \in M$ such that $x_{0} \preceq T x_{0}$; 
(ii) $T$ is continuous or $(M, \preceq, d)$ is regular.

Then $T$ has a fixed point. Moreover, if for all $x, y \in F i x(T)$ either $x \preceq y$ or $y \preceq x$, we have uniqueness of the fixed point.

Proof. Define the mapping $\alpha: M \times M \rightarrow[0, \infty)$ by

$$
\alpha(x, y)=\left\{\begin{array}{l}
1 \text { if } x \preceq y \text { or } x \succeq y, \\
0 \text { otherwise. }
\end{array}\right.
$$

Clearly, $T$ is a generalized $\alpha-\psi$ contractive mapping, that is,

$$
\alpha(x, y) \psi\left(s^{3} d(T x, T y)\right) \leq \beta(\psi(E(x, y))) \psi(E(x, y)),
$$

for all $x, y \in M$. From condition (i), we have $\alpha\left(x_{0}, T x_{0}\right) \geq 1$. On the other hand, for all $x, y \in M$, from the monotone property of $T$, we have

$$
\alpha(x, y) \geq 1 \Longrightarrow x \succeq y \text { or } x \preceq y \Longrightarrow T x \succeq T y \text { or } T x \preceq T y \Longrightarrow \alpha(T x, T y) \geq 1 .
$$

So $T$ is $\alpha$-admissible. In case of $T$ is continuous, the existence of a fixed point is concluded from Theorem 5.14. Now, assume that $(M, \preceq, d)$ is regular. Let $\left\{x_{n}\right\}$ be a sequence in $X$ such that $\alpha\left(x_{n}, x_{n+1}\right) \geq 1$ for all $n$ and $x_{n} \rightarrow x \in M$ as $n \rightarrow \infty$. From the regularity hypothesis, there exists a subsequence $\left\{x_{n(k)}\right\}$ of $\left\{x_{n}\right\}$ such that $x_{n(k)} \preceq x$ for all $k$. It yields from the definition of $\alpha$ that $\alpha\left(x_{n(k)}, x\right) \geq 1$ for all $k$. In this case, the existence of a fixed point follows from Theorem 5.14. To prove the uniqueness, let $x, y \in M$. Due to the hypothesis, we have $\alpha(x, y) \geq 1$ and $\alpha(y, x) \geq 1$. Hence, by Theorem 5.15, we conclude the uniqueness of the fixed point.

The following results are immediate consequences of Corollary 6.11.

Corollary 6.12. Let $(M, \preceq)$ be a partially ordered set and $d$ be a b-metric on $X$ such that $(M, d)$ is complete . Let $T: M \rightarrow M$ be a nondecreasing mapping with respect to $\preceq$. Suppose that there exist functions $\beta \in \mathcal{F}$ and $\psi \in \Psi$ such that

$$
\psi\left(s^{3} d(T x, T y)\right) \leq \beta(\psi(d(x, y))) \psi(d(x, y))
$$

for all $x, y \in M$ with $x \succeq y$. Suppose also that the following conditions hold:

(i) there exists $x_{0} \in M$ such that $x_{0} \preceq T x_{0}$;

(ii) $T$ is continuous or $(M, \preceq, d)$ is regular.

Then $T$ has a fixed point. Moreover, if for all $x, y \in$ Fix $(T)$ either $x \preceq y$ or $y \preceq x$, we have uniqueness of the fixed point.

Remark 6.9. In fact, in all results above, one can take $s=1$ to conclude the existing results in the literature.

\section{APPLICATION}

As an application, we consider the following integral equation

$$
x(t)=h(t)+\int_{0}^{1} k(t, \xi) T(\xi, x(\xi)) d \xi, \quad \forall t \in[0,1] .
$$

Let $\Omega$ denote the class of non-decreasing functions $\omega:[0, \infty) \rightarrow[0, \infty)$ verifying

$$
(\omega(t))^{r} \leq t^{r} \omega\left(t^{r}\right), \quad \text { for all } r \geq 1 \text { and } \forall t \geq 0 .
$$

We will analyze equation (7.103) under the following assumptions:

$\left(a_{1}\right) h:[0,1] \rightarrow \mathbb{R}$ is a continuous function, 
$\left(a_{2}\right) T:[0,1] \times \mathbb{R} \rightarrow \mathbb{R}$ is a continuous function, $T(t, x) \geq 0$ and there exists $\omega \in \Omega$ such that for all $x, y \in \mathbb{R}$,

$$
|T(t, x)-T(t, y)| \leq \omega(|x-y|)
$$

with $w\left(t_{n}\right) \rightarrow \frac{1}{2^{r-1}}$ as $n \rightarrow \infty$ implies that $\lim _{n \rightarrow \infty} t_{n}=0$,

$\left(a_{3}\right) k:[0,1] \times[0,1] \rightarrow \mathbb{R}$ is continuous in $t \in[0,1]$ for every $\xi \in[0,1]$ and is measurable in $\xi \in[0,1]$ for all $t \in[0,1]$ such that $k(t, x) \geq 0$ and

$$
\int_{0}^{1} k(t, \xi) d \xi \leq \frac{1}{2^{3-\frac{3}{r}}}
$$

Consider the space $M=C([0,1])$ of continuous functions with the standard metric given by

$$
\rho(x, y)=\sup _{t \in[0,1]}|x(t)-y(t)|, \forall x, y \in C([0,1]) .
$$

Now, for $r \geq 1$, we define

$$
d(x, y)=(\rho(x, y))^{r}=\left(\sup _{t \in[0,1]}|x(t)-y(t)|\right)^{r}=\sup _{t \in[0,1]}|x(t)-y(t)|^{r}, \forall x, y \in C([0,1]) .
$$

Note that $(M, d)$ is a complete $b$-metric space with $s=2^{r-1}$.

Theorem 7.16. Under assumptions $\left(a_{1}\right)-\left(a_{3}\right)$, the equation (7.103) has a unique solution in $C([0,1])$.

Proof. We consider the operator $T: M \rightarrow M$ defined by

$$
T(x)(t)=h(t)+\int_{0}^{1} k(t, \xi) T(\xi, x(\xi)) d \xi, \quad t \in[0,1] .
$$

By virtue of our assumptions, $T$ is well defined (this means that if $x \in M$ then $T x \in M$ ). Also, for $x, y \in M$, we have

$$
\begin{aligned}
|T(x)(t)-T(y)(t)| & =\left|h(t)+\int_{0}^{1} k(t, \xi) T(\xi, x(\xi)) d \xi-h(t)-\int_{0}^{1} k(t, \xi) T(\xi, x(\xi)) d \xi\right| \\
& \leq \int_{0}^{1} k(t, \xi)|T(\xi, x(\xi))-T(\xi, y(\xi))| d \xi \\
& \leq \int_{0}^{1} k(t, \xi) \omega(|x(\xi)-y(\xi)|) d \xi .
\end{aligned}
$$

Since the function $\omega$ is non-decreasing, so

$$
\omega(|x(\xi)-y(\xi)|) \leq \omega\left(\sup _{t \in[0,1]}|x(\xi)-y(\xi)|\right)=\omega(\rho(x, y)) .
$$

Therefore

Now, we have

$$
|T(x)(t)-T(y)(t)| \leq \frac{1}{2^{3-\frac{3}{r}}} \omega(\rho(x, y)) .
$$

$$
\begin{aligned}
d(T x, T y) & =\sup _{t \in[0,1]}|T(x)(t)-T(y)(t)|^{r} \\
& \leq\left[\frac{1}{2^{3-\frac{3}{r}}} \omega(\rho(x, y))\right]^{r} \leq \frac{1}{2^{3 r-3}} d(x, y) \omega(d(x, y)) \\
& \leq \frac{1}{2^{3 r-3}} \omega(E(x, y)) E(x, y),
\end{aligned}
$$

that is,

$$
s^{3} d(T x, T y) \leq \beta(E(x, y)) E(x, y),
$$


where $s=2^{r-1}$ and $\beta(t)=\omega(t)$. Notice that, if $\omega \in \mathcal{F}$, so $\beta \in \mathcal{F}$. By Corollary 6.9, equation (7.103) has a unique solution in $C[0,1]$ and the proof is completed.

\section{APPENDIX}

Lemma 8.4. Let $(X, \mu)$ be a measure space such that $\mu(X)=1$. Take $f \in L^{1}(X, \mu)$ satisfying the condition $T(x)>0$ for all $x \in M$. Then, $\ln (f) \in L^{1}(X, \mu)$ and

$$
\int \ln (f) d \mu \leq \ln \left(\int f d \mu\right) \text {. }
$$

Proof. Put $g(t):=t-1-\ln (t)$ and $h(t):=1-\frac{1}{t}-\ln (t)$ for $t>0$. Then, $g^{\prime}(t)=1-\frac{1}{t}$ and $h^{\prime}(t)=\frac{1}{t^{2}}-\frac{1}{t}$. Clearly, notice that

$$
g(t) \geq g(1)=0 \quad \text { and } \quad h(t) \leq h(1)=0 \quad \forall t>0 .
$$

We deduce

$$
t-1 \geq \ln (t) \geq 1-\frac{1}{t} \quad \forall t>0 .
$$

Since $T$ is measurable and $\ln$ is continuous, then $\ln (f)$ is measurable. Now, for all $x \in M$ let $t=\frac{T(x)}{\|f\|_{1}}$ in (8.104). So, we have

$$
1-\frac{\|f\|_{1}}{T(x)} \leq \ln (T(x))-\ln \left(\|f\|_{1}\right) \leq \frac{T(x)}{\|f\|_{1}}-1 .
$$

Since both right hand and left hand of $\left[\ln (T(x))-\ln \left(\|f\|_{1}\right)\right]$ is integrable, so $\ln (T(x))-\ln (\|$ $\left.f \|_{1}\right)$ is integrable. We also have

$$
\int\left(\ln (T(x))-\ln \left(\|f\|_{1}\right) d \mu \leq \int\left(\frac{T(x)}{\|f\|_{1}}-1\right) d \mu=0 .\right.
$$

Therefore,

$$
\int \ln (f) d \mu \leq \ln \left(\int f d \mu\right)
$$

\section{REFERENCES}

[1] J. Achari, On Ćirić's non-unique fixed points, Mat. Vesnik, 13 (28)no. 3, 255-257 (1976).

[2] H. Afshari, H. Aydi, E.Karapinar, Existence of Fixed Points of Set-Valued Mappings in b-Metric Spaces, East Asian mathematical journal , volume 32, issue 3, 2016, Pages 319 332, DOI : 10.7858/eamj.2016.024

[3] H. Afshari, H. Aydi and E. Karapinar, On generalized $\alpha-\psi$-geraghty contractions on $b$-metric spaces, Georgian Math. Journal, DOI: https://doi.org/10.1515/gmj-2017-0063.

[4] R. P. Agarwal, H. Alsulami, E.Karapınar and F.Khojasteh, Remarks on some recent fixed point results in quaternion-valued metric spaces, Abstract and Applied Analysis, (2014) Article Id: 171624

[5] U.Aksoy, E. Karapinar and I. M. Erhan, Fixed points of generalized alpha-admissible contractions on b-metric spaces with an application to boundary value problems,Journal of Nonlinear and Convex Analysis, (2016). Volume 17,Number 6, 1095-1108

[6] Ali and Kamran, On $\alpha^{*}-\psi$-contractive multi-valued mappings, Fixed Point Theory and Appl. 2013 2013:137.

[7] M. U. Ali, T. Kamran, E. Karapinar, On $(\alpha, \psi, x)$-contractive multi-valued mappings, Fixed Point Theory Appl., 2014, 2014:7 doi:10.1186/1687-1812-2014-7.

[8] H. Alsulami, S.Gulyaz, E. Karapinar, I. Erhan, An Ulam stability result on quasi-b-metric-like spaces, Open Mathematics, Volume 14, Issue 1 (Jan 2016) DOI 10.1515/math-2016-0097,

[9] H. Alsulami, S. Almezel, E. Karapinar, F. Khojasteh, A note on fixed point results in complex valued metric spaces, Journal of Inequalities and Applications, 2015, 2015:33

[10] H. H. Alsulami, E. Karapınar, F. Khojasteh, A. F. Roldán-López-de-Hierro, A proposal to the study of contractions in quasi-metric spaces, Discrete Dynamics in Nature and Society 2014, Article ID 269286, 10 pages. 
[11] H. H. Alsulami, E. Karapýnar, V. Rakocevic Ciric Type Nonunique Fixed Point Theorems on b-Metric Spaces, Filomat 31:11 (2017), 3147-3156

[12] P. Amiri, S. Rezapour, N. Shahzad, Fixed points of generalized $\alpha-\psi$-contractions, Revista de la Real Academia de Ciencias Exactas, Fisicas y Naturales Serie A Mate., doi: 10.1007/s13398-013-0123-9.

[13] H. Aydi, M-F. Bota, E. Karapinar and S. Mitrović, A fixed point theorem for set-valued quasi-contractions in b-metric spaces, Fixed Point Theory Appl. 2012, 2012:88.

[14] H. Aydi, M-F. Bota, E. Karapınar and S. Moradi, A common fixed point for weak $\phi$-contractions on b-metric spaces, Fixed Point Theory, 13(2012), No 2, 337-346.

[15] H. Aydi, E. Karapınar, B.Samet, Fixed points for generalized $(\alpha-\psi)$-contractions on generalized metric spaces, Journal of Inequalities and Applications 2014, 2014:229

[16] I.A. Bakhtin, The contraction mapping principle in quasimetric spaces, Funct. Anal., Unianowsk Gos. Ped. Inst. 30(1989), 26-37.

[17] S. Banach, Sur les opérations dans les ensembles abstraits et leur application aux équations intégrales, Fund. Math. 3 (1922) 133-181.

[18] V. Berinde, Generalized contractions in quasimetric spaces, Seminar on Fixed Point Theory, Preprint no. 3(1993), 3-9.

[19] V. Berinde, Sequences of operators and fixed points in quasimetric spaces, Stud. Univ. "Babeş-Bolyai", Math., 16(4)(1996), 23-27.

[20] V. Berinde, Contracţii generalizate şi aplicaţii, Editura Club Press 22, Baia Mare, 1997.

[21] N. Bilgili, E. Karapınar, A note on "Common fixed points for $(\psi, \alpha, \beta)$-weakly contractive mappings in generalized metric spaces", Fixed Point Theory Appl. 2013, 2013:287.

[22] R.M. Bianchini, M. Grandolfi, Transformazioni di tipo contracttivo generalizzato in uno spazio metrico, Atti Acad. Naz. Lincei, VII. Ser., Rend., Cl. Sci. Fis. Mat. Natur. 45 (1968), 212-216.

[23] M. F. Bota-Boriceanu, A. Petruşel, Ulam-Hyers stability for operatorial equations, Analel Univ. Al. I. Cuza, Iaşi, 57(2011), 65-74.

[24] M.-F. Bota, E. Karapinar and O. Mlesnite, Ulam-Hyers stability results for fixed point problems via alpha-psicontractive mapping in b-metric space, Abstract and Applied Analysis, 2013 Article Id: 825293

[25] M. Boriceanu, A. Petruşel, I.A. Rus, Fixed point theorems for some multivalued generalized contractions in b-metric spaces, International Journal of Mathematics and Statistics, 6(2010), 65-76.

[26] M. Boriceanu, Strict fixed point theorems for multivalued operators in b-metric spaces, IJMM, Vol 4, 3(2009), 285-301.

[27] M. Boriceanu, Fixed point theory for multivalued generalized contraction on a set with two b-metrics, Studia Univ. BabeşBolyai, Mathematica, 3(2009), 3-14.

[28] M. Bota, Dynamical Aspects in the Theory of Multivalued Operators, Cluj University Press, 2010.

[29] N. Bourbaki, Topologie Générale, Herman, Paris, 1974.

[30] J. Brzdek, J. Chudziak, and Z. Pales, A fixed point approach to stability of functional equations, Nonlinear Analysis: Theory, Methods and Applications, vol. 74, no. 17, pp. 6728-6732, 2011.

[31] J. Brzdek and K. Ciepliski, A fixed point approach to the stability of functional equations in non-Archimedean metric spaces, Nonlinear Analysis: Theory, Methods and Applications, vol. 74, no. 18, pp. 6861-6867, 2011.

[32] J. Brzdek and K. Cieplinski, A fixed point theorem and the Hyers-Ulam stability in non-Archimedean spaces, Journal of Mathematical Analysis and Applications, vol. 400, no. 1, pp. 68-75, 2013.

[33] L.B.Ćirić, On some maps with a nonunique fixed point. Publ. Inst. Math., 17, 52-58 (1974).

[34] S. Czerwik, Contraction mappings in b-metric spaces, Acta Mathematica et Informatica Universitatis Ostraviensis 1(1993), 5-11.

[35] S. Czerwik, Nonlinear set-valued contraction mappings in b-metric spaces, Atti Sem. Mat. Univ. Modena, 46(1998), 263-276.

[36] T.Došenovic, M. Postolache and S. Radenovic, On multiplicative metric spaces: survey Fixed Point Theory and Applications20162016:92

[37] W.-S. Du, A note on cone metric fixed point theory and its equivalence Nonlinear Analysis 72 (2010), no : 5, 2259-2261.

[38] M. Fréchet Sur quelques points du calcul fonctionnel, Rendic. Circ. Mat. Palermo 22 (1906) 1-74.

[39] S.Gupta and B. Ram, Non-unique fixed point theorems of Ćirić type, (Hindi) Vijnana Parishad Anusandhan Patrika 41( 4), 217-231(1998).

[40] F. Hausdorff. Mengenle hre . W. de Gruyter \& Co. , 1927.

[41] J. Hasanzade Asl, Sh. Rezapour and N. Shahzad, On fixed points of $\alpha-\psi$-contractive multifunctions, Fixed Point Theory and Applications, 2012(2012), doi:10.1186/1687-1812-2012-212.

[42] N.Hussain, J.R. Roshan, V. Parvaneh and M.Abbas, Common fixed point results for weak contractive mappings in ordered b-dislocated metric spaces with applications Journal of Inequalities and Applications (2013) 2013:486 
[43] N. Hussain, Z. Kadelburg, S. Radenović, and F.Al-Solamy, Comparison Functions and Fixed Point Results in Partial Metric Spaces, Abstract and Applied Analysis, vol. 2012, Article ID 605781, 15 pages, 2012.

[44] J. Heinonen, Lectures on Analysis on Metric Spaces, Springer Berlin, 2001.

[45] D. H. Hyers, On the stability of the linear functional equation, Proceedings of the National Academy of Sciences of the United States of America, vol. 27, no. 4, pp. 222-224, 1941.

[46] M. Jleli and B. Samet, Remarks on $G$-metric spaces and fixed point theorems, Fixed Point Theory Appl. 2012, 2012:210, 7 pages.

[47] E. Karapinar, H. Piri and H. AlSulami, Fixed Points of Generalized F-Suzuki Type Contraction in Complete bMetric Spaces,", Discrete Dynamics in Nature and Society, 2015 (2015), Article ID 969726, 8 pages

[48] E. Karapinar, H.Piri and H.H. AlSulami, Fixed Points of Generalized F-Suzuki Type Contraction in Complete b-Metric Spaces" Discrete Dynamics in Nature and Society, 2015 (2015), Article ID 969726, 8 pages

[49] E. Karapinar, A New Non-Unique Fixed Point Theorem, J. Appl. Funct. Anal. , 7 (2012),no:1-2, 92-97.

[50] E. Karapinar, Some Nonunique Fixed Point Theorems of Ćiric type on Cone Metric Spaces, Abstr. Appl. Anal., vol. 2010, Article ID 123094, 14 pages (2010).

[51] E. Karapinar, H. Piri and H. AlSulami, Fixed Points of Generalized F-Suzuki Type Contraction in Complete $b-$ Metric Spaces,", Discrete Dynamics in Nature and Society, 2015 (2015), Article ID 969726, 8 pages

[52] E. Karapinar, P. Kuman, P. Salimi, On $\alpha-\psi$-Meri-Keeler contractive mappings, Fixed Point Theory Appl. 2013:94 (2013)

[53] E. Karapınar, H.H. Alsulami and M. Noorwali, Some extensions for Geragthy type contractive mappings Journal of Inequalities and Applications 2015:303 (2015)

[54] E. Karapınar, B.Samet, Generalized $\alpha-\psi$-Contractive Type Mappings and Related Fixed Point Theorems with Applications Abstract and Applied Analysis Volume 2012, Article ID 793486, 17 pages

[55] E. Karapinar and W.-S. Du, A note on $b$-cone metric and its related results: Generalizations or equivalence? Fixed Point Theory and Applications, (2013), 2013:210

[56] F. Khojasteh, S. Shukla, S. Radenović, A new approach to the study of fixed point theorems via simulation functions, Filomat 29:6 (2015), 1189-1194.

[57] M.A. Kutbi , E. Karapinar, J. Ahmed, A. Azam, Some fixed point results for multi-valued mappings in $b$-metric spaces , Journal of Inequalities and Applications 2014, 2014:126

[58] A. Latif, M. E. Gordji, E. Karapınar, W. Sintunavarat, Fixed point results for generalized $(\alpha, \psi)$-Meir-Keeler contractive mappings and applications, J. Ineq. Appl. 2014, 2014:68.

[59] V. La Rosa, P. Vetro, Common fixed points for $\alpha-\psi-\varphi$-contractions in generalized metric spaces, Nonlinear Anal. Model. Control 19 (2014), no. 1, 43-54

[60] V. L. Lazăr, Ulam-Hyers stability for partial differential inclusions, Electronic Journal of Qualitative Theory of Differential Equations, 21 (2012), 1-19.

[61] Liu, Z. Q.: On Ćirić type mappings with a nonunique coincidence points, Mathematica (Cluj) 35(58),no. 2, 221225(1993).

[62] Liu, Z., Guo, Z., Kang, S. M., Lee, S. K.: On Ćirić type mappings with nonunique fixed and periodic points, Int. J. Pure Appl. Math., 26(3),399-408 (2006).

[63] B. Mohammadi, S. Rezapour, N Shahzad, Some results on fixed points of $\alpha$ - $\psi$-Ciric generalized multifunctions. Fixed Point Theory Appl., 2013 2013:24 doi:10.1186/1687-1812-2013-24.

[64] J.J. Nieto, R. Rodríguez-López, Contractive Mapping Theorems in Partially Ordered Sets and Applications to Ordinary Differential Equations, Order. 22 (2005) 223-239.

[65] B. G. Pachpatte, On Ćirić type maps with a nonunique fixed point, Indian J. Pure Appl. Math., 10( 8), 1039-1043 (1979).

[66] M. Păcurar, A fixed point result for $\varphi$-contractions on b-metric spaces without the boundedness assumption, Fasc. Math., 43(2010), 127-137.

[67] T. P. Petru, A. Petruşel and J.-C. Yao, Ulam-Hyers stability for operatorial equations and inclusions via nonself operators, Taiwanese Journal of Mathematics, Vol. 15, No. 5, pp. 2195-2212, October 2011.

[68] O. Popescu, Some new fixed point theorems for $\alpha$-Geraghty-contraction type maps in metric spaces, Fixed Point Theory Appl. 2014, 2014:190

[69] A.C.M. Ran, M.C.B. Reurings, A fixed point theorem in partially ordered sets and some applications to matrix equations, Proc. Amer. Math. Soc. 132 (2003) 1435-1443.

[70] I. A. Rus, The theory of a metrical fixed point theorem: theoretical and applicative relevances, Fixed Point Theory, 9(2008), No. 2, 541-559.

[71] I. A. Rus, Generalized contractions and applications, Cluj University Press, Cluj-Napoca, 2001.

[72] I. A. Rus, Remarks on Ulam stability of the operatorial equations, Fixed Point Theory, 10(2009), No. 2, 305-320. 
[73] I. A. Rus, A. Petruşel, A. Sîntămărian, Data dependence of the fixed points set of some multivalued weakly Picard operators, Nonlinear Anal. 52(2003), 1947-1959.

[74] P. Salimi, A. Latif, N. Hussain, Modified $\alpha-\psi$-contractive mappings with applications, Fixed Point Theory Appl., 2013 2013:151 doi:10.1186/1687-1812-2013-151.

[75] B. Samet, C. Vetro, P. Vetro, Fixed point theorems for $\alpha$ - $\psi$-contractive type mappings, Nonlinear Analysis 75 (2012), 2154-2165.

[76] B. Samet, C.Vetro, and F.Vetro, Remarks on $G$-Metric Spaces, International Journal of Analysis, Volume 2013 (2013), Article ID 917158, 6 pages

[77] S. Shukla, Partial b-Metric Spaces and Fixed Point Theorems, Mediterr. J. Math., 11 (2014)' 703711

[78] S. M. Ulam, Problems in Modern Mathematics, John Wiley and Sons, New York, NY, USA, 1964.

[79] A. F. Roldán-López-de-Hierro, E. Karapınar, C. Roldán-López-de-Hierro, J. Martínez-Moreno, Coincidence point theorems on metric spaces via simulation functions, J. Comput. Appl. Math. 275 (2015) 345-355.

[80] S. Radenović, Z. Kadelburg, D. Jandrlić and A. Jandrlić, Some results on weak contraction maps, Bulletin of the Iranian Mathematical Society Vol. 38 No. 3 (2012), pp 625-645.

[81] M. Turinici, Abstract comparison principles and multivariable Gronwall-Bellman inequalities, J. Math. Anal. Appl. 117 (1986) 100-127.

\author{
ATILIM UNIVERSITY, \\ DEPARTMENT OF MATHEMATICS \\ 06836, İNCEK, ANKARA, TURKEY. \\ E-mail address: erdalkarapinar@yahoo.com
}

